\title{
Characterising the dynamics of surface water-groundwater interactions in intermittent and ephemeral streams using streambed thermal signatures
}

\author{
Gabriel C. Rau ${ }^{\mathrm{a}, \mathrm{b}, *}$, Landon J. S. Halloran ${ }^{\mathrm{a}, \mathrm{b}}$, Mark O. Cuthbert ${ }^{\mathrm{a}, \mathrm{c}}$, Martin \\ S. Andersen ${ }^{\mathrm{a}, \mathrm{b}}$, R. Ian Acworth ${ }^{\mathrm{a}, \mathrm{b}}$, John H. Tellam ${ }^{\mathrm{d}}$ \\ ${ }^{a}$ Connected Waters Initiative Research Centre, School of Civil and Environmental \\ Engineering, UNSW Sydney, Australia \\ ${ }^{b}$ Water Research Laboratory, School of Civil and Environmental Engineering, UNSW \\ Sydney, Australia \\ ${ }^{c}$ Department of Geography, University College London, United Kingdom \\ ${ }^{d}$ School of Geography, Earth and Environmental Sciences, University of Birmingham, \\ United Kingdom
}

\begin{abstract}
Ephemeral and intermittent flow in dryland stream channels infiltrates into sediments, replenishes groundwater resources and underpins riparian ecosystems. However, the spatiotemporal complexity of the transitory flow processes that occur beneath such stream channels are poorly observed and understood. We develop a new approach to characterise the dynamics of surface water-groundwater interactions in dryland streams using a pair of temperature records measured at different depths within the streambed. The approach exploits the fact that the downward propagation of the diel temperature fluctuation from the surface depends on the sediment thermal diffusivity. This is controlled by time-varying fractions of air and water contained in streambed sediments causing a contrast in thermal properties. We demonstrate the usefulness of this method with multi-level temperature and pressure records of a flow event acquired using 12 streambed arrays deployed along a $\sim 12 \mathrm{~km}$ dryland channel section. Thermal signatures clearly indicate the presence of water and characterise the vertical flow component as
\end{abstract}

*. Corresponding author : Connected Waters Initiative Research Centre \& Water Research Laboratory, 110 King Street, Manly Vale NSW 2093, Australia

Email address: gabriel.rau@unsw.edu.au (Gabriel C. Rau) 
well as the occurrence of horizontal hyporheic flow. We jointly interpret thermal signatures as well as surface and groundwater levels to distinguish four different hydrological regimes : $[\mathrm{A}]$ dry channel, $[\mathrm{B}]$ surface run-off, $[\mathrm{C}]$ poolriffle sequence, $[\mathrm{D}]$ isolated pools. The occurrence and duration of the regimes depends on the rate at which the infiltrated water redistributes in the subsurface which, in turn, is controlled by the hydraulic properties of the variably saturated sediment. Our results have significant implications for understanding how transitory flows recharge alluvial sediments, influence water quality and underpin dryland ecosystems.

Keywords: surface water-groundwater interactions; ephemeral and intermittent streams; heat as a tracer; hydrological characterisation; streambed thermal regimes

\section{$1 \quad$ Highlights}

2 - Amplitude ratios of the daily temperature component at two different 3 depths in the streambed can be used to distinguish dry from saturated $4 \quad$ sediment

5 - Multi-level streambed temperature records reveal distinct thermal si$6 \quad$ gnatures that characterize water flow

$7 \quad$ - Ephemeral or intermittent surface water-groundwater interactions can 8 be categorized into a sequence of hydrological regimes 


\section{Introduction}

The spatial and temporal movement of water through dry stream channels and the surrounding shallow sediments is highly dynamic. Stream flow cessation and drying occur in more than half of the world's river networks [1] with proportions exceeding $80 \%$ in dryland regions [2. Water in otherwise dry channels recharges groundwater through infiltration [e.g., 3, 4, 5, 6, 7] and underpins dryland ecological diversity [e.g., 8, 2]. In fact, shallow groundwater is often the only source of freshwater for human and ecosystem activity during periods of dry climate and therefore of critical importance [9, 10, 11].

As groundwater resources are being depleted globally [12, the largest water stresses exist in areas with high population and low surface water availability [13] and are intensified by human activity [14. Because groundwater recharge in dryland regions is predominantly due to infiltration of water during flow events (i.e., 'focused' or 'indirect') [e.g., 9, 5], understanding temporary surface-groundwater interactions is of paramount importance [6, 7]. However, monitoring temporary flow events is challenging and thus observations are scarce [15, 16].

The presence of water in otherwise dry channels is generally referred to as 'ephemeral' or 'intermittent' behaviour depending on the duration of flow [e.g., 17]. When such streams are flowing, the degree of interaction between the surface and groundwater systems depends on complex hydrogeologic controls [18, 19, 20]. The spatiotemporal dynamics of such surface watergroundwater interactions in these contexts are currently poorly understood [7.

It is recognised that streambed temperature data provides useful insight into the flow dynamics of dryland systems especially when complementing pressure data. Daily stream temperature oscillations can cause variations in stream discharge which relate to infiltration caused by the change in water physical properties [3, 21]. Constantz and Thomas [15, 22] found that streambed temperature can be used as an indicator of streamflow and can provide subsurface water percolation characteristics. Constantz et al. [16] and Blasch et al. 23] determined streamflow frequency and duration using streambed temperature records. Constantz et al. [24] numerically modelled subsurface temperature records and concluded that percolation rates could be constrained. While much of this work, summarised in Blasch et al. [25], illustrates the temporal dynamics of transient surface-groundwater interactions, interpretation is limited by data from discrete spatial locations. 
Here, we draw from the large body of heat tracing knowledge developed for surface-groundwater interactions in perennial (saturated) systems [e.g., refer to the reviews of 26, 27, 28 and extend the methodologies to include consideration of dry systems. We exploit the fact that the presence of water in otherwise dry sediments changes the thermal properties [e.g., 15, 29, 30, 31].

In reality, sediments can be variably saturated, i.e. during the wetting and drying stages of a flow event. In fact, streambed sediments may never be entirely dry or fully saturated. However, we limit our analysis to realistic end-members of dry and water saturated conditions as the resulting thermal contrast is large enough to allow reliable detection of water. This simplification also avoids overly complicated saturation measurements and equations that are necessary when coupling the non-linear processes involved in variably saturated conditions. For details about heat tracing to infer variably saturated processes or properties we refer the interested reader to Halloran et al. [30, 31].

In this paper we demonstrate that (1) streambed temperature data can be interpreted to distinguish reliably between approximately dry and saturated conditions below dryland streams, thus allowing identifications of stream flow episodes; (2) temperature records, interpreted using this approach, can be used to distinguish between dominantly upward, downward, and horizontal flow below dryland streams; (3) the qualitative results can be used to constrain conceptual models of temporary surface-groundwater interactions. Our results have significant implications for improving the evaluation of focused or indirect groundwater recharge and can underpin further research on water quality and ecohydrology in dryland streams.

\section{Theoretical background}

\subsection{Propagation of diel temperature fluctuations into shallow sediments}

The analysis of heat tracing data utilizes the diel temperature fluctuations that ubiquitously occur at the Earth's surface and propagate vertically downwards into the subsurface where the thermal wave is both damped and delayed over depth [32, 33]. For a 1D vertical section of water saturated (wet) near-surface sediment exposed to sinusoidal temperature forcing at the 
surface, the temperature over depth and time can be described as [33, 34]

$$
T^{s a t}(z)=T_{0}+A \cdot \exp \left[\frac{z}{2 D}\left(v-\sqrt{\frac{\alpha+v^{2}}{2}}\right)\right] \cdot \cos \left[\frac{2 \pi t}{P}-\frac{z}{2 D} \sqrt{\frac{\alpha-v^{2}}{2}}\right],
$$

where $T_{0}$ is the ambient temperature $\left[{ }^{\circ} \mathrm{C}\right], A$ is the diel temperature amplitude $\left[{ }^{\circ} \mathrm{C}\right], z$ is vertical depth $[\mathrm{m}]$ (positive $=$ down), $t$ is time $[\mathrm{s}], P$ is the period of the sine wave $[\mathrm{s}], v$ is the thermal front velocity linearly related to Darcy flux $q$. The parameter $\alpha$ is defined as

$$
\alpha=\sqrt{v^{4}+\left(\frac{8 \pi D}{P}\right)^{2}}
$$

and the sediment bulk thermal diffusivity is [35, 26]

$$
D=\frac{\kappa}{\rho c}
$$

where $\kappa$ is the thermal conductivity $\left[\mathrm{Wm}^{-1} \mathrm{~K}^{-1}\right], \rho$ is the density $\left[\mathrm{kgm}^{-3}\right]$ and $c$ is the specific heat capacity $\left[\mathrm{Jkg}^{-1} \mathrm{~K}^{-1}\right]$ of the sediments; $\rho c$ is the thermal capacity $\left[\mathrm{Jm}^{-3} \mathrm{~K}^{-1}\right]$ [36]. The thermal parameters depend on the sediment moisture conditions (dry or saturated) and are discussed in Section 2.2. In this investigation we neglect thermal dispersivity as is justified for water fluxes $v<10 \mathrm{~m} / \mathrm{d}$ 37.

Heat tracing is best conducted using a pair of temperature sensors that are arranged vertically. The advantage is that the sensor spacing, rather than absolute depth, can be targeted or precisely measured. In this case an amplitude ratio can be defined for water saturated streambeds [38]

$$
A_{r}^{s a t}\left(\Delta z, D^{s a t}, v\right)=\frac{A_{2}\left(z_{2}\right)}{A_{1}\left(z_{1}\right)}=\exp \left[\frac{\Delta z}{2 D^{s a t}}\left(v-\sqrt{\frac{\alpha+v^{2}}{2}}\right)\right]
$$

where $A_{1}$ and $A_{2}$ are the amplitude of diel temperature fluctuations measured at discrete depths in the sediment $\left(\left|z_{2}\right|>\left|z_{1}\right|\right)$.

Analytical heat tracing has been widely used to calculate vertical water fluxes under water saturated conditions [e.g. 27, 28]. We note that in the case of uniform directional flow and in the absence of hydrodynamic thermal dispersion, this approach delivers the vertical flow component of the total flow vector [39]. 


\subsection{Heat tracing to distinguish between dry and water saturated sediments}

Streambed sediments can undergo variably water saturated conditions depending on whether the channel is dry or wet, i.e. the presence of air in the sediments [40]. Consequently, the corresponding difference in thermal parameters must be considered. The bulk thermal diffusivity in Equation 3 has a non-linear dependency on saturation [41, 42, 31. Côté and Konrad [41] presented a generalized thermal conductivity model for variably saturated sediment which we simplify to its dry and saturated end-members. The thermal conductivity for dry streambeds is [41]

$$
\kappa^{d r y}=\chi \cdot 10^{-\eta n}
$$

where $\chi$ and $\eta$ are empirical parameters that depend on the grain size; here, we use $\chi=1.7$ and $\eta=1.8$ for rocks and gravels as is most suitable for dryland channels exposed to high energy flows; $n$ represents the total porosity [-] of the sediment. In contrast, the saturated thermal conductivity is given as 43, 41, 42,

$$
\kappa^{s a t}=\kappa_{w}^{n} \cdot \kappa_{s}^{(1-n)}
$$

where subscripts $w$ and $s$ represent water and solid matrix, respectively.

The thermal capacity of a sediment with two phases (dry : air and solid matrix, saturated : water and solid matrix) is defined as a porosity weighted volumetric mean [44, 36, 31]

$$
\begin{gathered}
(c \rho)^{d r y}=(1-n)(c \rho)_{s} \\
(c \rho)^{s a t}=n(c \rho)_{w}+(1-n)(c \rho)_{s}
\end{gathered}
$$

where subscripts $w$ and $s$ represent water and solid matrix, respectively. The specific heat capacity of air is so small that it can be neglected in our analysis 31].

Thermal diffusivity for water saturated $\left(D^{\text {sat }}\right)$ and dry $\left(D^{d r y}\right)$ sediment can be calculated by using Equation 3 in combination with Equations 6 and 8 or Equations 5 and 7, respectively.

Under the conditions of water saturated streambed sediments, the amplitude ratio $A_{r}^{\text {sat }}$ (Equation 4) is a function of the bulk saturated thermal diffusivity of the sediment $D^{\text {sat }}$ and the thermal front velocity (determined by the vertical flow of water $), A_{r}^{\text {sat }}\left(D^{s a t}, v\right)$. For dry streambed sediments, the amplitude ratio will only depend upon the bulk dry sediment thermal 
diffusivity $D^{d r y}$ because the absence of water also means that $v=0$ (no flow). Consequently, under dry conditions Equation 4 can be simplified to

$$
A_{r}^{d r y}\left(\Delta z, D^{d r y}\right)=\frac{A_{2}\left(z_{2}\right)}{A_{1}\left(z_{1}\right)}=\exp \left[-\Delta z \sqrt{\frac{\pi}{P D^{d r y}}}\right] .
$$

This equation can be reformulated to calculate the dry bulk sediment thermal diffusivity $D^{d r y}$ from the ratio of the diel temperature amplitudes measured using two sensors located at different depths during a period when the streambed is dry.

In reality, streambed thermal properties and porosity can vary within natural limits. Significant effort towards additional field measurements would be required to constrain these parameters, as the phase shift of the thermal wave cannot be used to separate the sediment thermal conductivity or specific heat capacity from thermal diffusivity. Note also that calculation of the saturated streambed thermal diffusivity is hindered by the degree of freedom introduced through a variable vertical water flux and is therefore impossible to accomplish without independent flow measurements.

To determine whether there is always a difference in amplitude ratio for dry and saturated sediments, given the range of natural parameter variability, we evaluated $\Delta A_{r}^{d r y, s a t}=A_{r}^{s a t}-A_{r}^{d r y}$ as a function of the respective thermal diffusivity values. Note that for a given location in space, the thermal properties of the solid matrix, as well as the porosity, remain constant during any change from dry to saturated. While the thermal property values for water are accurately defined (Table 1), the three unknown properties are : The streambed porosity $n$ (which we allow to vary between 0.2 and 0.5 ), solid thermal conductivity $\kappa_{s}$ (low porosity volcanic rocks [46]), and solid thermal capacities $(c \rho)_{s}$ (rock forming minerals 36]).

Figure 1 a shows the resulting $\Delta A_{r}^{d r y, s a t}$ as multi-parameter space at discrete values of porosity over the range of thermal parameters. This illustrates that the diel temperature amplitude is significantly different for a realistic range of dry and water saturated streambed sediments, $A_{r}^{d r y}<A_{r}^{\text {sat }}$. This is because during a flow event the streambed pore space, initially occupied by air, will be replaced with water with significantly different thermal properties. A change in $A_{r}$ can, therefore, be used to distinguish between realistic end-members of water saturation (dry vs. saturated), and therefore acts as an easily measurable proxy for streambed flow processes. 


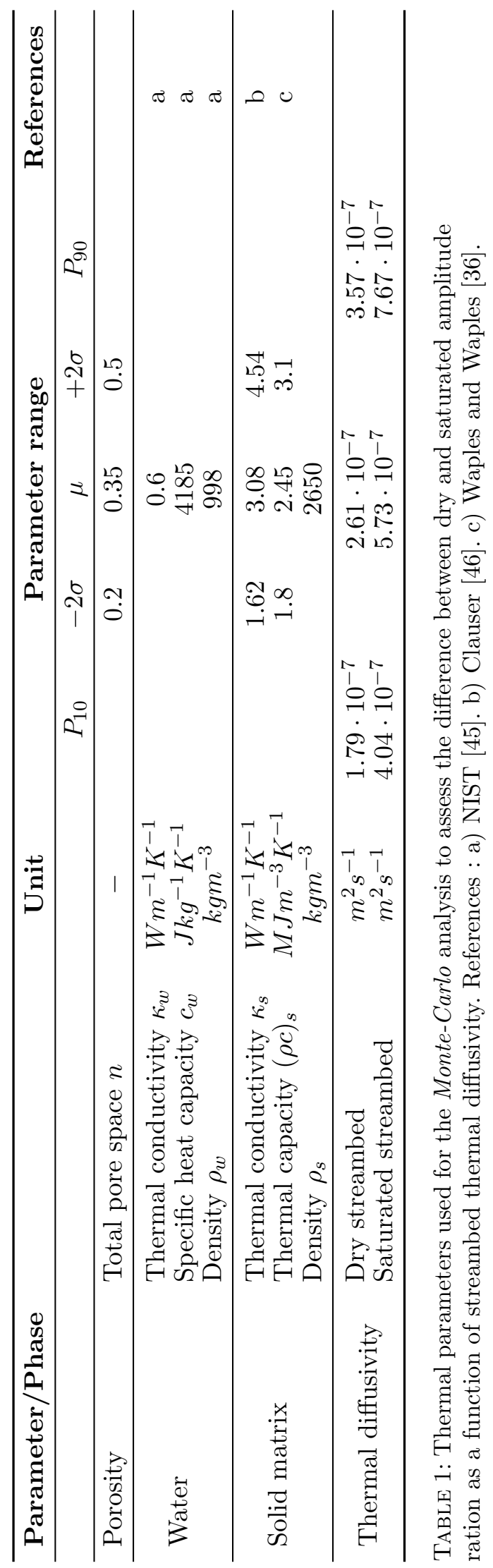




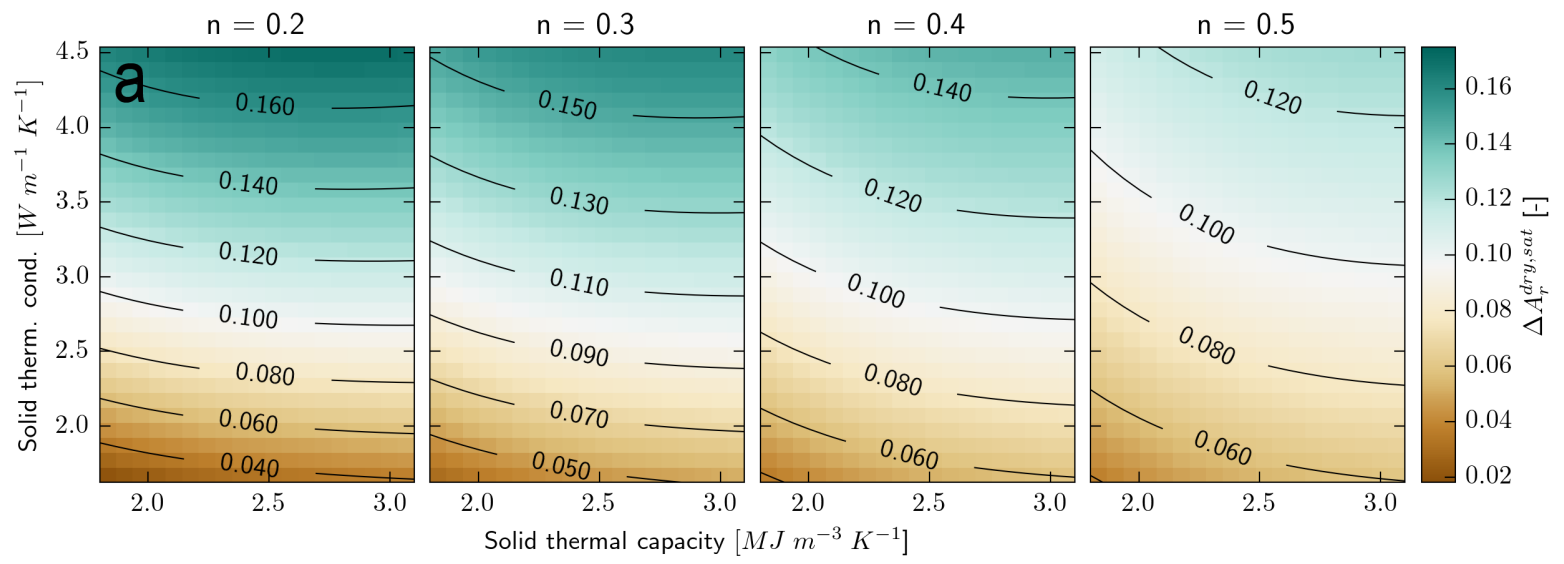

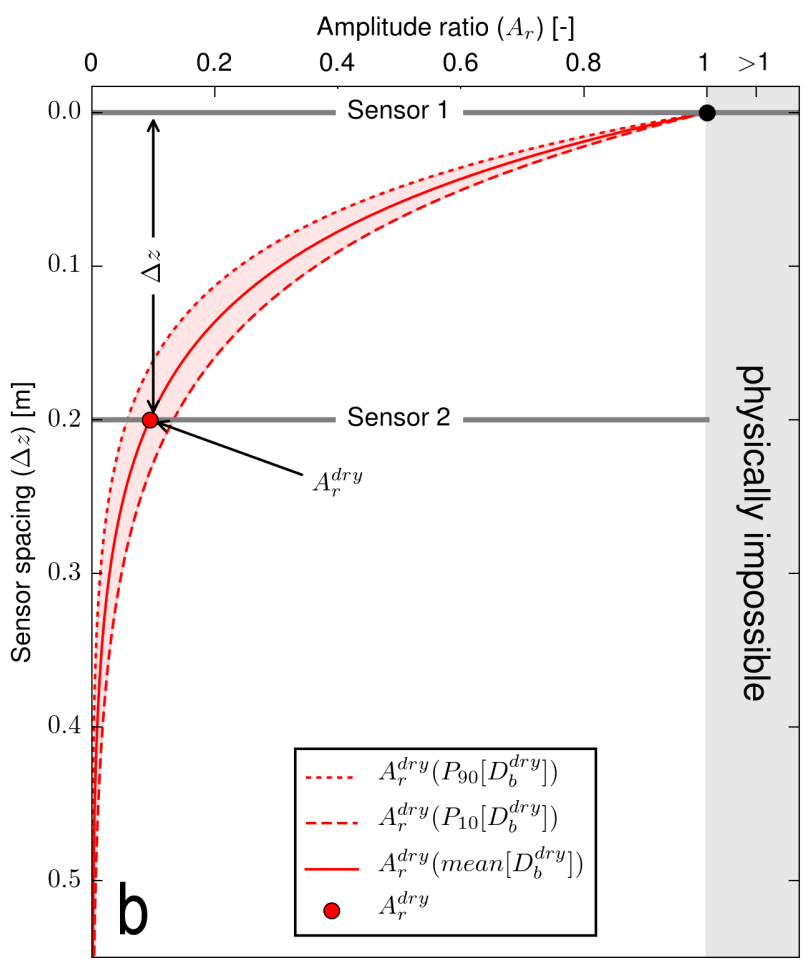

(a) dry streambed

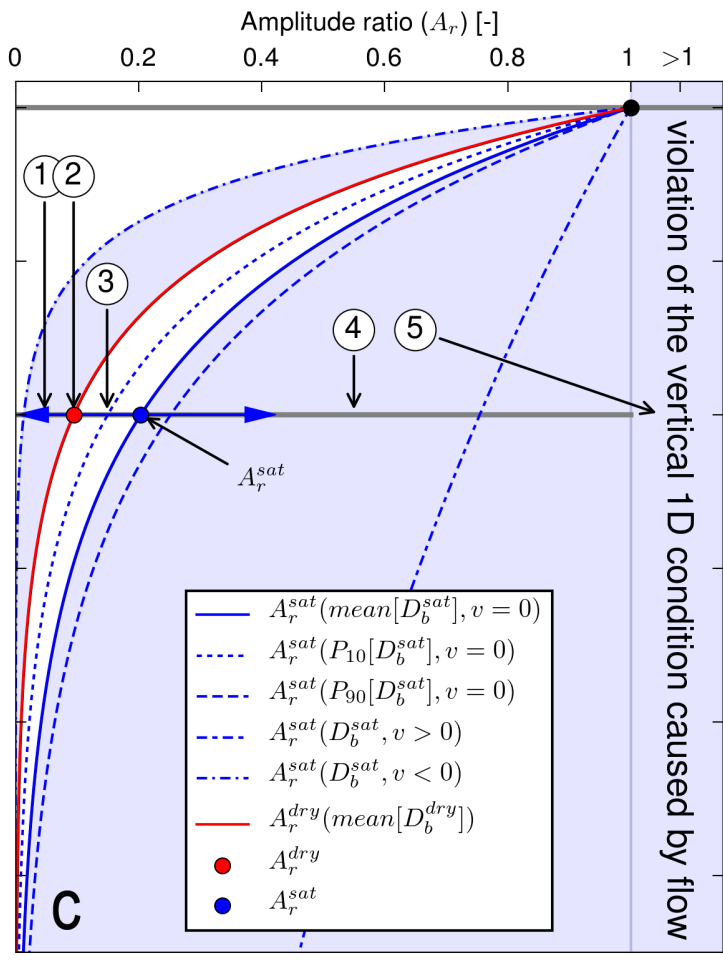

(b) saturated streambed

FiguRE 1: Conceptual model illustrating how to characterize the dynamics of ephemeral surface-groundwater interactions in shallow variably saturated sediments using the diel temperature amplitude ratio $\left(A_{r}\right)$ as a signature : a) The likely range of the diel temperature amplitude ratio for dry and saturated streambeds (resulting from a range of porosity and thermal parameters) is shown for an example sensor spacing $\Delta z=0.2 \mathrm{~m}$ and thermal front velocities of $v= \pm 1 \mathrm{~m} / \mathrm{d}$. b) The thermal diffusivity of wet streambed sediments is different leading to a change in amplitude ratio during flow. Further, changes in amplitude ratio can indicate the vertical direction of water fluxes in the sediments between the temperature sensors. This can be used to characterise ephemeral surface-groundwater interactions during flow events. c) The difference between dry and saturated $(v=0)$ amplitude ratio $\Delta A_{r}$ as a function of a range in solid thermal conductivity $\kappa_{s}$ and solid thermal capacity $(\rho c)_{s}$ at discrete porosity values. Numbered labels 1-5 are explained in the text. 


\subsection{Shallow streambed thermal signatures detect water and characterize flow} through variably saturated streambed sediments

To estimate the saturated streambed thermal diffusivity $\Delta A_{r}^{d r y, s a t}$ can be used. We performed a Monte-Carlo analysis (100,000 samples) to establish the most likely values for dry and saturated amplitude ratio as a function of streambed thermal diffusivity. We use the literature derived ranges shown in Table 1 as input assuming that all properties follow a normal distribution and that $95.4 \%$ of the existing values fall within these limits (i.e., $\mu \pm 2 \sigma$ ). The resulting mean and percentile $\left(P_{10}\right.$ and $\left.P_{90}\right)$ values for dry and saturated streambed thermal diffusivity are listed in Table 1. These values were used to plot the amplitude-depth relationships in Figure $1 \mathrm{~b}$ and $1 \mathrm{c}$ and visualise the difference between dry and saturated $A_{r}$.

Figure 1 demonstrates that the $A_{r}$ can be divided into the following categories (see corresponding labels in Figure 1c) :

(1) $0<A_{r}(t)<A_{r}^{d r y}:$ Water saturated sediment and a vertical upward flow component.

(2) $A_{r}(t)=A_{r}^{d r y}$ : Dry end-member of the streambed sediments which can be established from temperature records acquired during dry periods.

(3) $A_{r}^{d r y}<A_{r}(t) \leq A_{r}^{\text {sat }}:$ A small range of ambiguity where the exact conditions are unclear, i.e. variable water saturation or fully saturated with a flow component ranging between vertical upward and zero. Here, Monte-Carlo analysis offers a measure of the uncertainty to compare with the difference between $A_{r}^{d r y}$ and $A_{r}^{s a t}\left(0.02<\Delta A_{r}<0.175\right.$, Figure 1a). We note that interpretations can still be made when temperature data are acquired in conjunction with pressure, as values are indicative of the presence of water above the point of measurement.

(4) $A_{r}^{\text {sat }}<A_{r}(t) \leq 1$ : Water saturated sediment and larger values for an increasing vertical downward flow component.

(5) $A_{r}(t)>1$ : Water-saturated sediment and conditions that violate the $1 \mathrm{D}$ vertical flow assumption inherent to Equation 1. This has been observed previously [47] and can, in the absence of a daily fluctuating subsurface heat source, only be caused by horizontal hyporheic flow.

To simplify the approach we only consider the end-members of saturation, close to dry and water saturated. In reality, there could be variable saturation in the streambed sediments, particularly during the onset of flow and drying 
of the channel. During times of variable water saturation, the amplitude ratio will be between $A_{r}^{d r y}$ and $A_{r}^{\text {sat }}$.

Figure 1 clearly illustrates that under realistic conditions, the saturated amplitude ratio $A_{r}^{\text {sat }}$ (Equation 44) should always be larger than the dry amplitude ratio $A_{r}^{\text {dry }}$ (Equation 9), i.e. $\Delta A_{r}>0$. The diel amplitude ratio $A_{r}$, therefore, allows detection of the moisture state, i.e. dry or saturated, as well as characterization of vertical water movement through sediments when the system is near the saturated end-member.

In this method we abstain from quantifying infiltration rates because this would require knowledge of the streambed moisture content during flow events as well as the associated thermal diffusivity. In our approach, the zone of $A_{r}$ ambiguity due to variable moisture content occupies values representative of saturated conditions and upward water flow. Given that streams with temporary flow are generally hydraulically disconnected from the groundwater table [e.g. 48, 6], water will most likely percolate downwards at least as long as a variably saturated zone remains. Under these conditions, $A_{r}(t)$ should serve as a novel indicator revealing the streambed processes during ephemeral or intermittent flow.

\subsection{Extraction of the diel amplitudes from temperature measurements}

Equation 1 requires that the temperature forcing is a sinusoidal wave. This is not a realistic assumption under real-world conditions. However, we can capitalise on the fact that any signal can be decomposed into a finite sum of sinusoidal components using the Discrete Fourier Transform. This is necessary so that the resulting signal component complies with the conditions inherent to Equation 1, and that the amplitude of a single frequency component (e.g., daily) can be used directly with $A_{r}$ in Equations 4 and 9 .

To calculate diel temperature amplitudes a Fast Fourier Transform (FFT), as implemented in Python, can be applied to subsets of the data which span a multiple number of days. The FFT of a signal is defined as

$$
\hat{s}\left(f_{k}\right)=\mathcal{F}\left\{s\left(t_{n}\right)\right\}=\sum_{n=0}^{N-1} s\left(t_{n}\right) e^{-2 \pi i k n / N}
$$

where $k$ and $n$ denote the indices of discretely sampled frequency and time, respectively, which range from 0 to $N-1$. It is not important to normalize the transform as long as data treatment is consistent and ratios of the amplitudes 
are used. The discrete frequencies of the transformed signal are

$$
f_{k}=k f_{s} / N \text {. }
$$

For a window of $i$-multiple days, the absolute value of the $i$-th entry $f_{i}$

$$
A\left(f_{i}\right)=\left|\hat{s}\left(f_{i}\right)\right|=\sqrt{\mathcal{R}^{2}\left(f_{i}\right)+\mathcal{I}^{2}\left(f_{i}\right)}
$$

corresponds to the amplitude of the $f=1 \mathrm{cpd}$ (cycles per day) frequency component [30]. This procedure is repeated as a rolling window along the time series whereby $A\left(f_{i}\right)$ is allocated to the time at the center of the window.

Using this approach, a temperature amplitude time series can be extracted and used to calculate amplitude ratios from Equation 4. Ephemeral flow events can be characterised using the methodology described earlier. It is important to neglect extracted amplitude values that are below the temperature resolution of commonly available sensors, i.e. $A>0.01^{\circ} \mathrm{C}$ can be considered valid. Theoretically, the component phases could also be extracted and used. However, Rau et al. [49] noted that signal non-stationarity, as inherent in natural temperature oscillations, causes erroneous phase results which significantly decreases the accuracy of any phase-derived calculations.

\section{Field example from Middle Creek in the Maules Creek Catch- ment, New South Wales, Australia}

\subsection{Catchment context}

The Maules Creek catchment is located in the semi-arid northwestern area of New South Wales (NSW), Australia (Figure 2). Middle Creek flows into Horsearm Creek, then Maules Creek and further into the Namoi River which is a tributary of the large Murray-Darling Basin (MDB) (Figure 21). The Nandewar range provides the northern and eastern margin of the catchment and consists of Miocene basaltic mountains peaking at 1,506 m (Mt. Kaputar) Australian Height Datum (AHD). The Namoi River at the western part of the catchment is at approx. $230 \mathrm{~m}$ AHD. The difference in topography causes a significant orographic rainfall effect resulting in a long-term average rainfall of $928 \mathrm{~mm} / \mathrm{a}$ in the mountains (Mt. Kaputar at $1450 \mathrm{~m}$ AHD) and $561 \mathrm{~mm} / \mathrm{a}$ on the floodplain (Narrabri Bowling Club at $229 \mathrm{~m}$ AHD and only $35 \mathrm{~km}$ west of Mt. Kaputar).

A major change in geology separates the Carboniferous and Devonian rocks in the upper catchment from the Permian lower catchment. The Carboniferous and Devonian metasediments and intrusives have been thrust over 
the Permian Mauls Creek coal measures to the west with the thrust zone occurring at the mountain front between T11 and T10 (Figure 2). The high energy flows from the mountains have cut 10 to $15 \mathrm{~m}$ deep channels into the coal measures that are now filled with a very heterogeneous assemblage of boulders, sand and gravels that are substantially reworked by each major flood.

This catchment area has been well instrumented for groundwater monitoring since 2009 through the Australian Government National Collaborative Infrastructure Strategy (NCRIS). A number of research projects were conducted mainly in the lower part of the catchment : Andersen and Acworth [50] surveyed the perennial surface-groundwater interactions and noted the complexity of these processes. Rau et al. 47] successfully quantified the rate of saturated vertical flow in the streambed using heat as a tracer. To evaluate the groundwater resources within the catchment, a comprehensive groundwater model was created and illustrated considerable uncertainty and a lack of information about groundwater recharge through the intermittent stream channels originating at the mountain front [51]. Further research on groundwater resources as well as surface water-groundwater interactions can be found in McCallum et al. [52], Kelly et al. [53] and Cuthbert et al. [7].

\subsection{Monitoring of rainfall, groundwater and streambed water levels and tem-} perature

Middle Creek drains an estimated $106 \mathrm{~km}^{2}$ of the upper catchment and the discharge point of which is located at the confluence with Horsearm Creek (Figure 2). Rainfall was recorded at weather stations using tipping bucket rain gauges (Campbell Scientific Inc., USA) at three different locations (see abbreviations in Figure 2b) : Mt Kaputar National Park (MK, Australian Government Bureau of Meteorology station \#54151), Middle Creek Farm (MCF) and Bellevue Farm (BVF). An additional long-term rainfall dataset is available from the Mount Lindsay Station (ML, Australian Government Bureau of Meteorology station \#54021) which has been operational since 1886 and located $\sim 11 \mathrm{~km}$ south-east of the Mt. Kaputar station. The Mount Lindsay Station has an elevation of $\sim 870 \mathrm{~m}$ but lies in a rain shadow of the higher Mt. Kaputar rain gauge.

The loggers used to measure streambed temperature and pressure were a combination of off-the-shelf devices : HOBO temp pro v2 (U22-02), Schlumberger Diver and Solinst Levelogger Gold/Edge. The temperature measured by the loggers was calibrated against a reference (Fluke hand-held 1524) in 

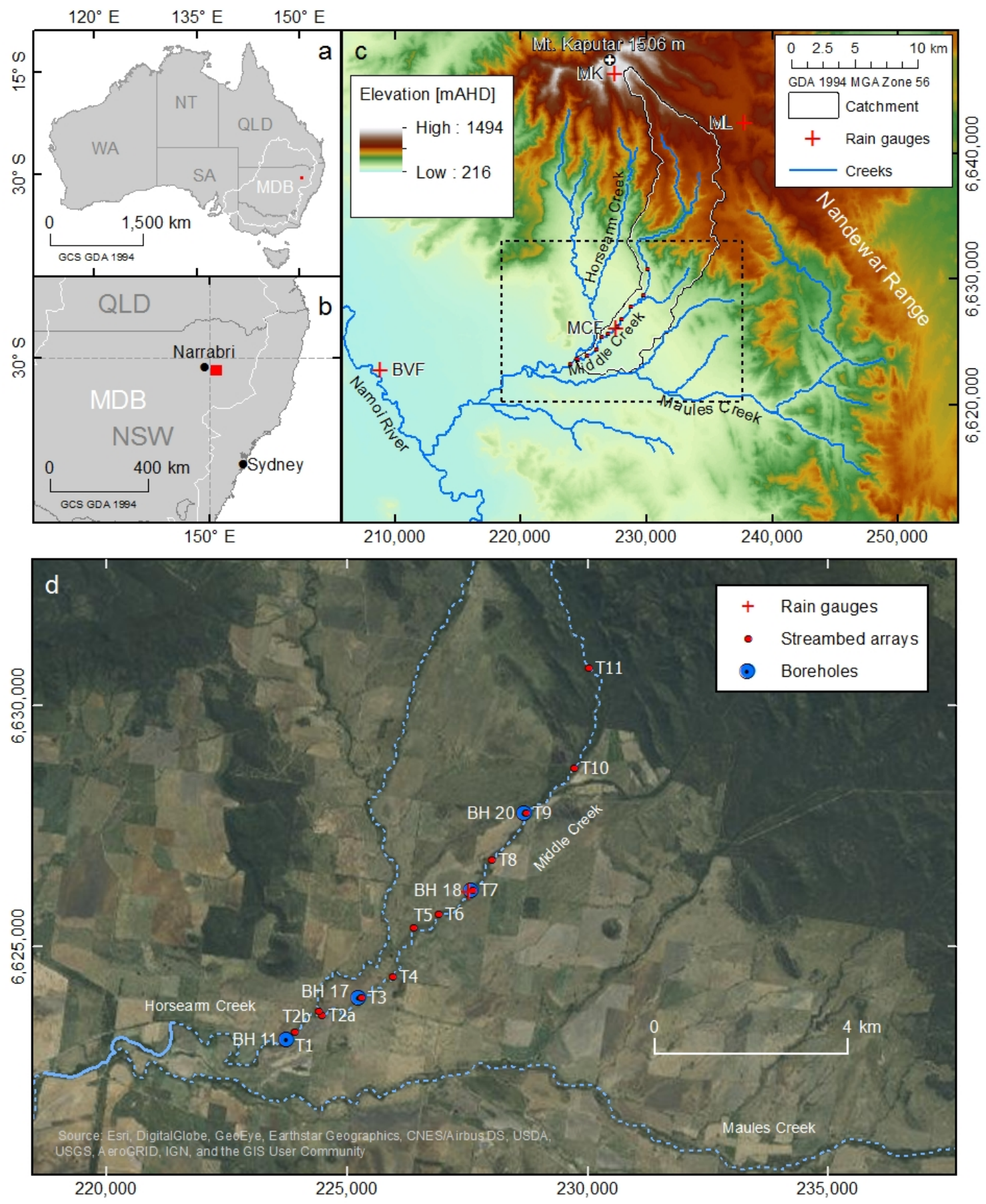

Figure 2: Map showing (a) the location the Maules Creek catchment in relation to the Murray-Darling Basin (MDB), (b) the state of New South Wales, (c) a catchment elevation map with locations of rain gauges, (d) streambed array installations and piezometers along Middle Creek. 


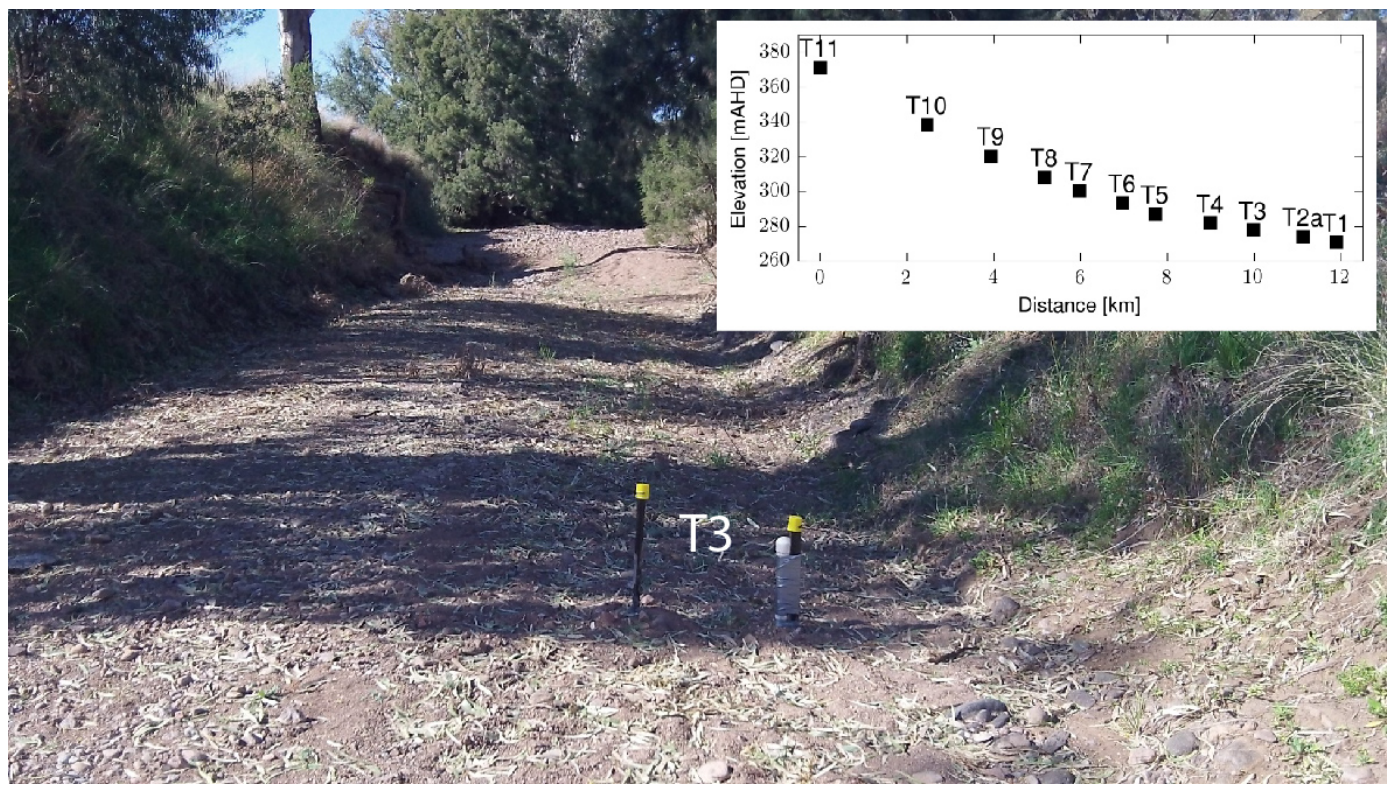

FiguRE 3: Streambed array T3 installed in the dry channel as an example representative of the other locations. Inset plot shows the distance-elevation profile for all arrays as surveyed using differential GPS (Table 2).

a bucket of well-stirred water at different values. The calibration was applied as a correction to the temperature field records.

Temperature and pressure were recorded at discrete depths in the shallow streambed at a total of 12 different locations along Middle Creek. Multi-level streambed arrays were constructed from $32 \mathrm{~mm}$ diameter standard hydraulic PVC pipe. Loggers were placed inside the pipe at defined intervals (multilevel monitoring), with the pressure measured at the top and bottom end, and separated by spacers [47, 54]. The effect of this array design on the measured diel amplitudes has been found to be negligible [55]. The length of the streambed arrays depended on the number of loggers used at the different locations of deployment. Table 2 contains the details of the streambed arrays.

Because the stream flow events can be high energy, installation of the arrays required the construction of an anchor point. At each location, two star pickets were manually driven into the streambed sediments in an $\mathrm{x}$ formation and a small pit was dug around the point of contact between the star pickets. The pit was then filled with quick-set concrete and covered with 
large cobbles. For an example installation please refer to Figure 3 .

Short arrays were directly attached to the star pickets with the uppermost sensor located at the same vertical level as the streambed. Longer, multilevel arrays were installed with the same method as described by [47] at $\sim 1$ $m$ downstream and securely attached to the anchor point. Streambed arrays were installed at the end of July 2013, and loggers were programmed to record pressure and temperature at 15 min intervals. The aim was to capture an entire flow event along the creek.

Geospatial coordinates of all installation points were accurately surveyed using differential GPS equipment (Trimble R10 GNSS). For a summary of streambed monitoring arrays, measured parameters and locations refer to Table 2, An atmospheric pressure record, obtained from the MCF weather station, was used to calculate gauge pressure and hydraulic heads in combination with the survey. The approximate flow distance between the first and last monitoring points was traced in $A r c M A P$ based on an identification of the channel from satellite imagery and is reported in Table 2 .

Multi-level boreholes were installed right next to the ephemeral stream channel (distance within tens of meters) as described by Cuthbert et al. 7]. To determine the hydraulic connectivity between surface flow and groundwater in the sediments along the channel (BH 11, BH 17, BH 18 and $\mathrm{BH} 20$ in Figure 2d), the shallower screens were monitored at 15 min intervals.

\subsection{Spatiotemporal surface and groundwater responses to a major rainfall event}

Cumulative rainfall of $329 \mathrm{~mm}, 198 \mathrm{~mm}$ and $228 \mathrm{~mm}$ was measured at MK, MCF and BVF, respectively, for the 60-day period from 20 March to 18 May 2016 (4). This rainfall occurred as clustered rain events with short periods of dry weather. The rainfall triggered mountain run-off and led to stream flow along the channel as recorded by the streambed arrays summarised in Figure 4. The rainfall amount was more than double the average long-term (1886-2012) moving 60-day sum of 155 mm (max. 809 mm in February 1971), indicating that it was a sizeable event for this catchment.

Figure 4 summarises the dynamics of water movement along Middle Creek, over depth and in time for this event. Note that the array (streambed surface) elevations almost perfectly follow an exponential curve (inset in Figure 3 based on data in Table 2). The run-off moved along the previously dry channel and was captured by the pressure transducers at the streambed as a hydrograph peak with differing heights. Water levels upstream (array T11) 


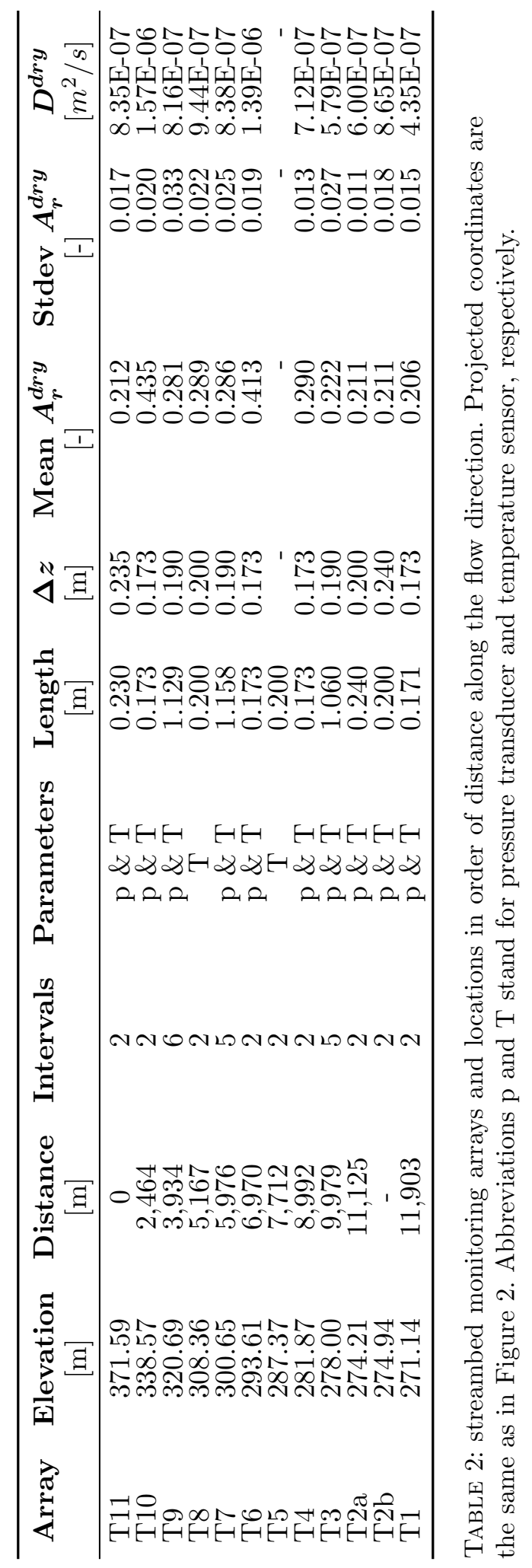


peaked on 28 Mar 2014 at $4: 15$. The flood took 135 min to move $\sim 11.9 \mathrm{~km}$ (Figure 2) to the downstream end (array T1) with an average velocity of $\sim 1.5 \mathrm{~m} / \mathrm{s}$. Note that array T8 and T5 did not contain pressure transducers.

The depth to groundwater (thickness of the unsaturated zone) along the stream channel (between BH20 and BH11) was variable before the flow event and generally decreased in the downstream direction. The shallow groundwater responds immediately to stream flow illustrating infiltration of surface water into the alluvial sediments and demonstrating an evolving connection between surface and groundwater [19, 56, 57].

The groundwater hydrograph responses vary at the four locations along the channel. For example, in the downstream locations (from T3 and BH 17 to $\mathrm{T} 1$ and $\mathrm{BH} 11$ ) the rapid movement of infiltrating surface water to the water table causes a peak in groundwater levels within days of the flow event followed by a steady decline. This is consistent with the conceptual model of groundwater redistribution beneath transitory streams that has been developed by Cuthbert et al. [7] and can be described by the aquifer response time (ART) defined as $t_{A R T}=\frac{L^{2} S_{y}}{2 T}$, where $L$ is a given length, $S_{y}$ is specific yield and $T$ is transmissivity. In contrast, the subsurface water mound upstream (from $\mathrm{T} 9$ and $\mathrm{BH} 20$ to $\mathrm{T} 7$ and $\mathrm{BH} 18$ ) increases and redistributes much more slowly as a temporary hydraulic connection to the groundwater is established [19]. Our water level measurements, when interpreted using results from a systematic numerical investigations of variations in groundwater head in response to surface flow [57], reveal that hydraulic properties of the alluvium are highly heterogeneous. For example, the responses measured upstream (BH18 and BH20) indicate that a low-permeability layer (or clogging layer) may exist beneath the stream and that the average hydraulic conductivity is lower compared to the downstream sites (BH11 and BH17).

The slower redistribution of water in the shallow aquifer results in far more prolonged surface flow than in the lower catchment. Note that the initially sharp rise in heads recorded at BH20 during the first few days of the flow event is likely due to a loading effect with the more gradual rise that follows being due to groundwater recharge due to streambed infiltration and lateral movement of groundwater.

Interestingly, the surface water hydrograph after the flood peak behaves differently for each array along the flow path (Figure 4). The upstream arrays show a gradual hydrograph flattening after the initial peak, followed by a stable water level for a period of time which spanned from $\sim 3$ to 6 weeks 


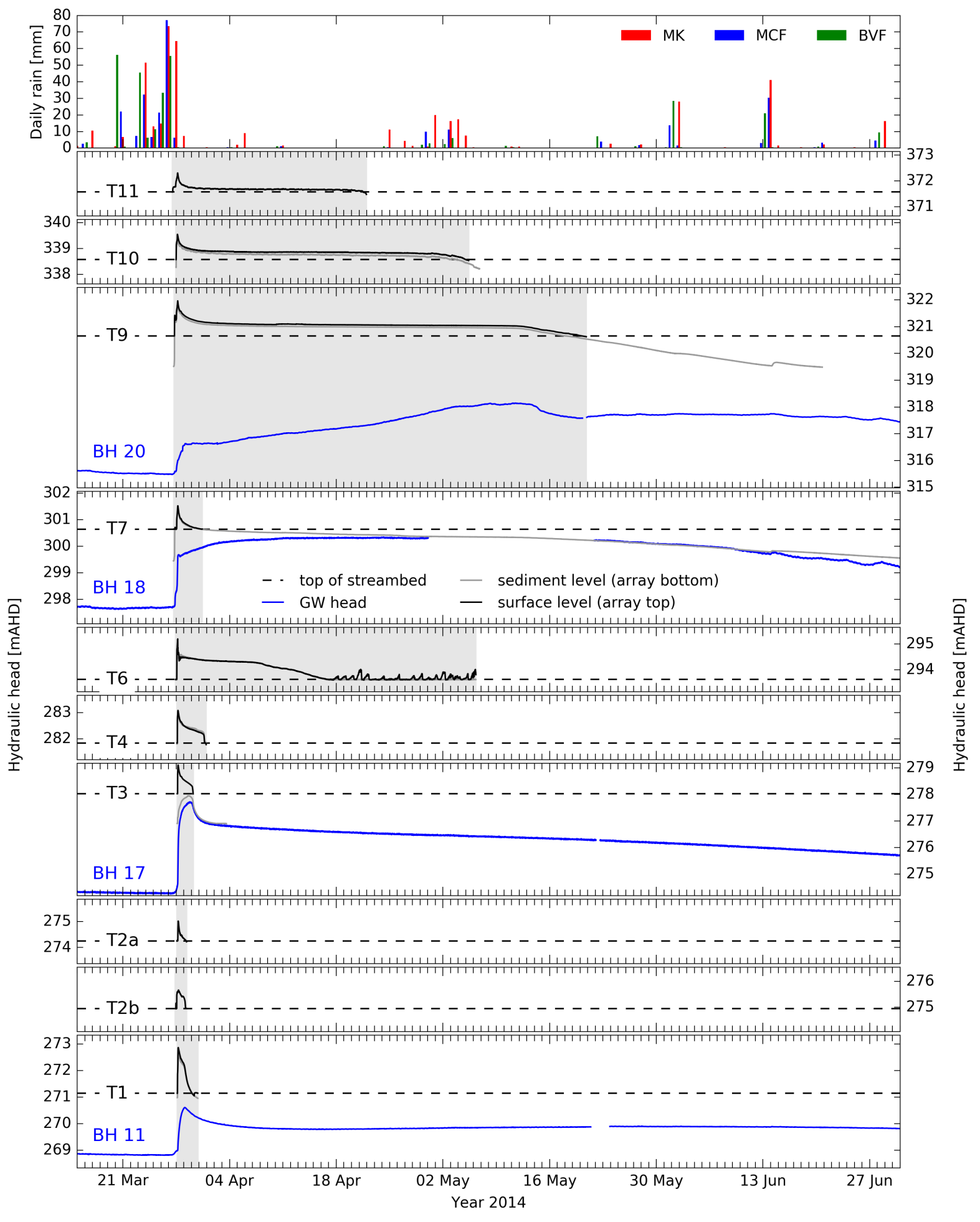

Figure 4: Daily rainfall recorded at three stations in the Maules Creek Catchment, hydraulic heads recorded by the streambed arrays installed along Middle Creek, including the nearby groundwater heads where available. Time periods when standing or flowing water was present at the streambed surface are highlighted in grey. Refer to Figure 2 for streambed array and borehole locations. Note that arrays T8 and T5 did not contain pressure transducers. 
for arrays located at the upper end of the alluvium. During this time surface water was contained in the stream channel. A steady but significant decline in water level followed this period of stable water level.

The difference in surface flow behaviour is clearly depicted in Figure 4 and is controlled by the rate of groundwater redistribution in the subsurface 7]. It is clear that much of the surface water is retained in the upper part of the channel (upstream from array T6, Figure 2) whereas the lower part of the creek shows short periods of surface run-off consistent with the behaviour of a disconnected ephemeral system [56, 6]. The cause of this behaviour is the subject of ongoing research beyond the scope of this paper, but it is likely controlled by the particle size distribution of the sediment and the general heterogeneity of the channel sediments [58, 20].

\subsection{Thermal conditions at the streambed surface}

Figure 5 illustrates the temperature data recorded by the uppermost pressure transducer of each array (located at the streambed surface) in individual time colour bars for each location along the channel. Note that the uppermost logger in array T5 failed during deployment and this location is therefore excluded from further analysis. The times when surface water was present, as indicated by the sensor measuring values above atmospheric pressure, are indicated as horizontal lines. The air temperature (MCF weather station), is plotted for comparison and varied between -0.7 and $33.5^{\circ} \mathrm{C}$ while the sediment surface temperatures varied between 2.7 and $45.4^{\circ} \mathrm{C}$.

A decrease in overall temperature reflects the transition between autumn and winter in the southern hemisphere. While there is an obvious correlation between the air and the streambed surface temperature, the diel temperature fluctuations are more pronounced at the streambed surface and vary depending on the array location. Thermal conditions at the streambed surface were affected by direct insolation during day time and differ depending on location settings caused by variable amounts of shading. The similarity of thermal conditions with low diel variability during the flow event is apparent.

The streambed surface temperatures clearly contain diel temperature oscillations modulated by mesoscale weather events (Figure 5). Figure 6] shows the diel amplitudes extracted from the air and streambed surface temperature records using FFT analysis. The range of air temperature amplitudes was between 1.1 and $9.7^{\circ} \mathrm{C}$, whereas the range of streambed surface temperature amplitudes ranged between 0 and $10^{\circ} \mathrm{C}$. A correlation between air and streambed surface temperature amplitudes is clearly visible in Figure 6 


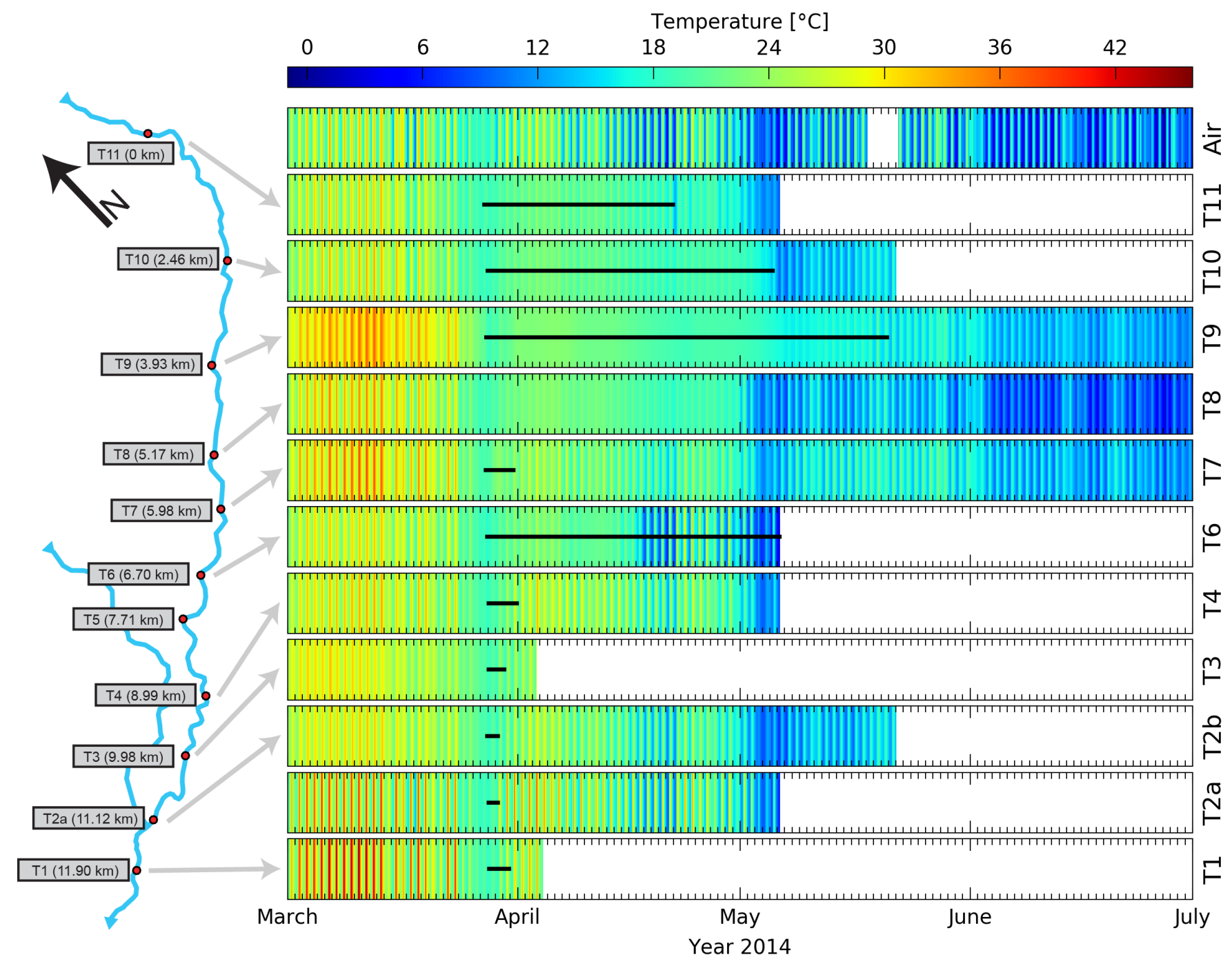

Figure 5: Temperatures recorded in the air and at the streambed surface along Middle Creek. Black lines indicate saturated conditions at the surface, i.e. the time during which the sensor was submerged in water. Note that the air temperature was not recorded during a small period in May 2014, that array T8 did not contain a pressure transducer, and that array $\mathrm{T} 5$ probe failed during deployment. 


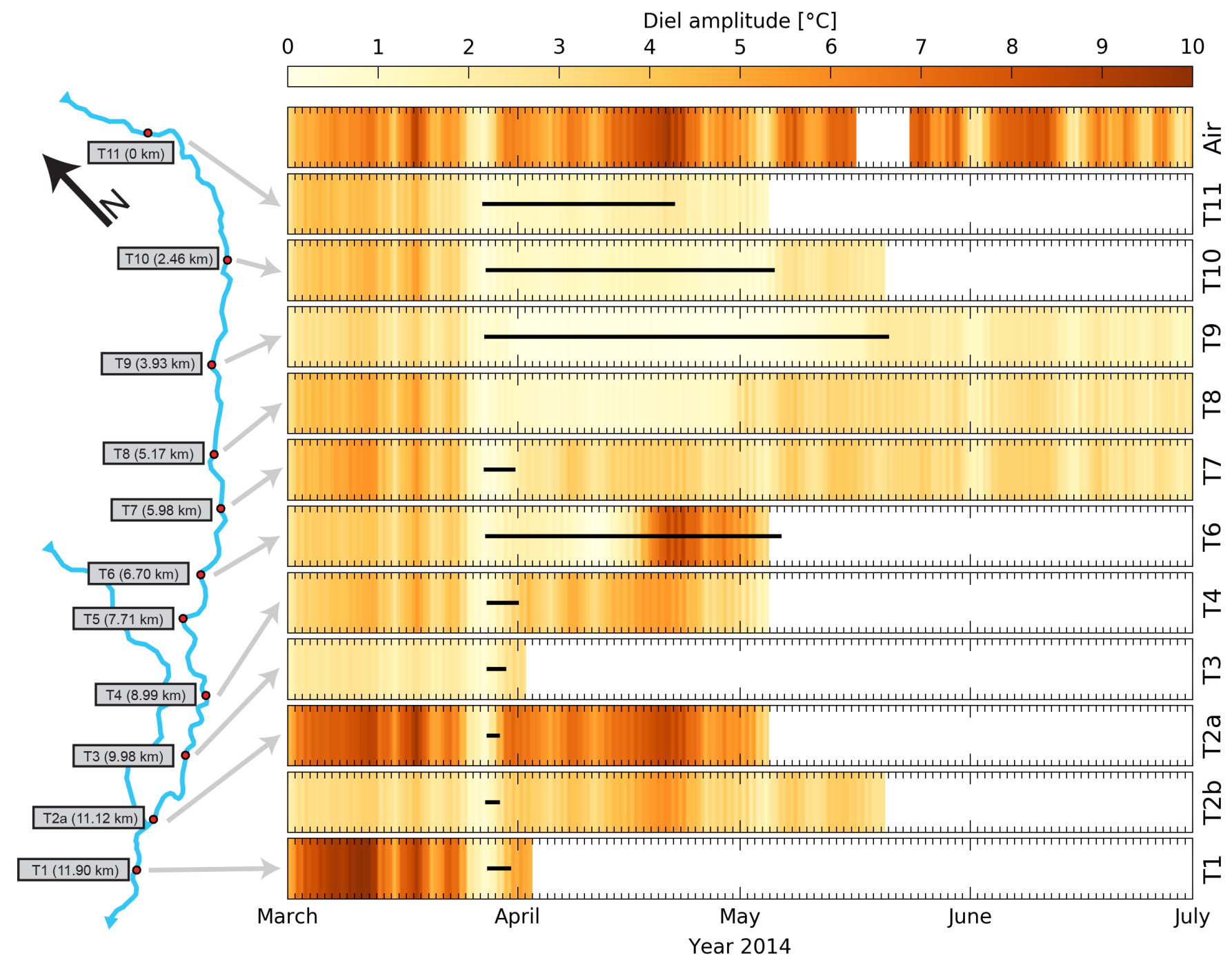

Figure 6: Amplitudes of the diel component of recorded temperature variations in the air and at the streambed surface along Middle Creek. Black lines indicate saturated conditions at the surface, i.e. the time during which the sensor was submerged in water. 
for periods when the streambed surface was dry. Diel amplitudes show significant damping during the flow event when ponded or flowing water was present at the streambed sediment surface.

As observed by Constantz et al. [16], the onset of flow is preceded by lower absolute temperatures and smoothed diel amplitudes associated with the mesoscale low-pressure system. Our measurements confirm that flow cannot be deduced from temperature measurements and extracted amplitudes alone.

\subsection{Streambed thermal signatures can detect the presence of water and cha-} racterise vertical water movement

If amplitude ratios for dry and saturated conditions can be calculated, then the vertical amplitude ratio time series in shallow streambed sediments (Figure 6) can be used to detect both the presence of water and to characterise the flow regimes according to the theory developed above. While $A_{r}^{d r y}$ can be evaluated from measurements during dry periods, $A_{r}^{\text {sat }}$ requires estimation based on the likely values established from Monte-Carlo analysis. Note that the difference between both values is relatively small $\left(\Delta A_{r}^{\text {dry,sat }}<0.12\right)$. Both values constrain a narrow range between them where the interpretation of vertical flow is ambiguous. However, as explained in Section 2.3, $A_{r}$ values outside that range are directly indicative of the direction and magnitude of vertical water flow.

The amplitude ratio $A_{r}^{d r y}$ for dry streambed sediments at each location was calculated using the diel amplitudes extracted from temperature records using FFT analysis between 8-15 March 2014, and values are summarised in Table 2. While thermal diffusivity results comply with those calculated from the Monte-Carlo analysis, they are higher than expected which indicates the presence of large sized grains. Visual inspection of the streambed sediments confirms this inference and many large cobbles can be seen in the foreground of Figure 3 [41.

During flow events (wet streambed conditions) the amplitude ratio will depend on the vertical streambed water flux (see Equation 4). Theoretically, the $A_{r}$ could be used to quantify this vertical flux [38, 59] and, provided that phases of the diel frequency components are also extracted, the saturated thermal diffusivity of the streambed could also be quantified [52, 60]. However, Rau et al. [49] demonstrated that analytical heat tracing methods fail to provide accurate results when the diel component in the temperature signal is non-stationary. This includes highly transient infiltration as is expected 


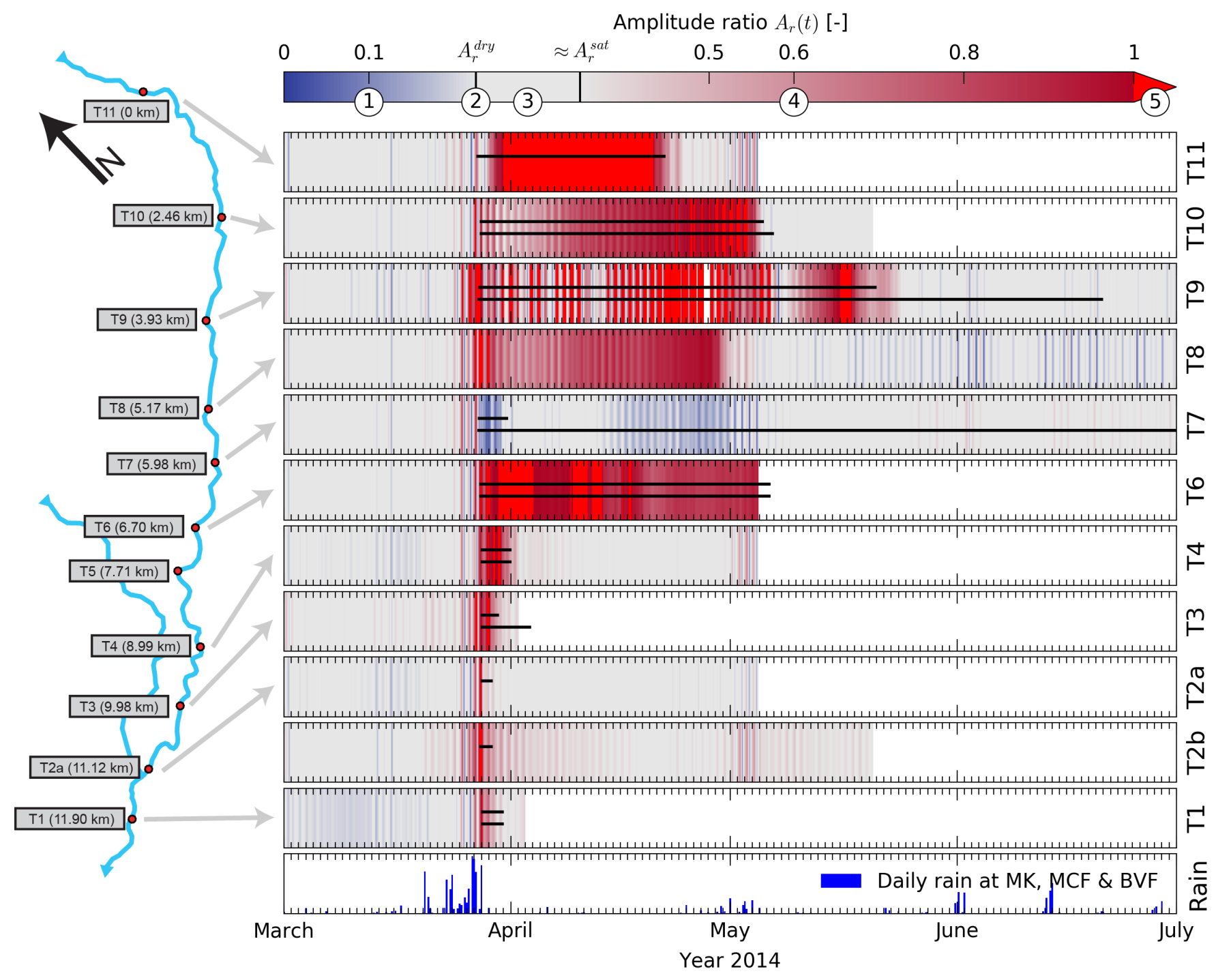

FiguRe 7: Diel temperature amplitude ratios $A_{r}$ between the uppermost pair of sensors in the streambed. The colour map is adapted for each location to correctly reflect : $A_{r}^{d r y}$ as established from measurements during a dry period, and $A_{r}^{\text {sat }}=A_{r}^{d r y}+\Delta A_{r}$ calculated using thermal diffusivity values from Monte-Carlo results as well as site-specific sensor spacings. The colours reflect saturated conditions, where increasing blue represents an increasing vertical upward flow component (1) and colours increasing towards red represent increasing vertical downward flow component (4). Red reflects periods during which the $A_{r}>1$ and indicates horizontal hyporheic flow (5). Black lines indicate wet conditions at the surface (top) and at depth (bottom) in the streambed, i.e. the times during which the loggers were submerged in water. The numbers along the colour bar correspond to the thermal signature characterizations defined in Section 2.3 and Figure 1 . The daily rain is plotted to show the influence on the streambed thermal regime. 
during the dynamic flow events which are characteristic of Middle Creek (Figure 4). We therefore abstain from using phase results in our analysis.

Figure 7 shows the amplitude ratio time series for all arrays along Middle Creek translated into colours that reflect the different categories explained in Figure 1. It is clear that $A_{r}$ can be used to distinguish between dry and saturated streambed conditions as confirmed by the pressure transducers detecting water (compare the black line with the coloured pattern representing $A_{r}$ variation). The influence of rainfall prior to the arrival of the surface run-off is also detected. Further, most arrays show variable downward water movement throughout the flow event (red colour corresponding to range 4 in Figure 1) as is expected for an intermittent system. The only exception is T7 which indicates upward movement during the period of surface run-off and is discussed later. Here, water is retained within the alluvium for a time period that exceeds all other locations, as indicated by the hydrograph measured by the sensor at the bottom of the streambed array (Figures 4).

The results in Figure 7 contain a wealth of information that could be attributed to processes that have been found to influence transitory SW-GW interactions. For example, it is widely accepted that the hydraulic properties of alluvial sediments are strongly heterogeneous which can lead to zones of variable saturation beneath the stream [61, 62]. A field investigation using moisture sensors to measure the temporal behaviour of infiltration has reported localised preferential flow which contributes to a rising water mound that can saturate the streambed from the bottom upwards [18]. An increase in saturation in the alluvial sediments due to infiltration may be considerably delayed after the onset of flow due to variability in sediment properties such as grain size [18, 63]. Moreover, certain combinations of channel geometry and stream water level can induce water saturation beneath the stream but without a saturated connection to the groundwater (inverted water table) 64].

We note that all these processes could affect the shallow streambed thermal diffusivity and therefore also the derived temperature amplitude ratios. As an example, T11 illustrates a thermal signature indicative of variably saturated sediment at the beginning of the flow event (Figure 7) during the same time as the pressure transducer clearly indicates the presence of surface water (Figure 4). This observation is in agreement with the previous findings of delayed saturation or rising water mound and illustrates that thermal signatures can enhance interpretation of the complexity of dryland SW-GW interactions, even more so when combined with water level measu- 
rements. We further note that thermal signatures and water levels acquired during multiple flow events can be used to reveal the temporal dynamics of infiltration over longer time scales which could enhance the interpretation of transience in streambed conductance[65]. This could further improve our understanding of the complex water flow dynamics at the variably saturated stream-aquifer interface.

\subsection{Streambed thermal regimes and spatio-temporal flow behaviour}

To characterise the thermal conditions during flow events, the hydraulic head and temperature records for two representative multi-level arrays were plotted for T9 in Figure 8 and for T7 in Figure 9. These plots include the temperature data measured at multiple levels within the topmost meter of the channel sediment and diel temperature amplitudes as extracted from the measurements using FFT analysis. Both streambed arrays contain the thermal signatures which are found in all other locations (Figure 7) and are therefore worthy of detailed inspection.

Figure 8 a clearly shows the temporal character of flow events measured at the location of streambed array T9. T7 shows a similar hydrograph measured by the pressure transducer at the bottom, but the one at the top only captured the peak of the flow event whereas the bottom logger remained submerged in water contained in the streambed for a period of time. From Figure 4 it is clear that all hydrographs which captured more than the initial peak illustrate a similar shape but with differing duration of the stable or receding water level (intermittent stream behaviour).

The following flow regimes can be derived from the observed hydrograph shapes, and are categorised below and illustrated in a conceptual model of transitory surface-groundwater interactions (Figure 10, colours refer to Figures 8 and 9 :

[A] Dry channel (red) as a default for dryland streams : The dry sediments are characterised by large temperature amplitudes at the surface that is rapidly damped with depth for both T9 (Figure 8b) and T7 (Figure 9b). The large amplitudes at the boundary are a result of insolation and indicate dry conditions (absence of water). The $A_{r}$-depth profile for a location, as shown in Figures $8 \mathrm{~d}$ and $9 \mathrm{~d}$, can be used to benchmark the thermal conditions in the dry streambed.

[B] Rapid surface run-off (green) : Surface run-off and infiltration along the channel may result in a spatially heterogeneous distribution of alluvium 

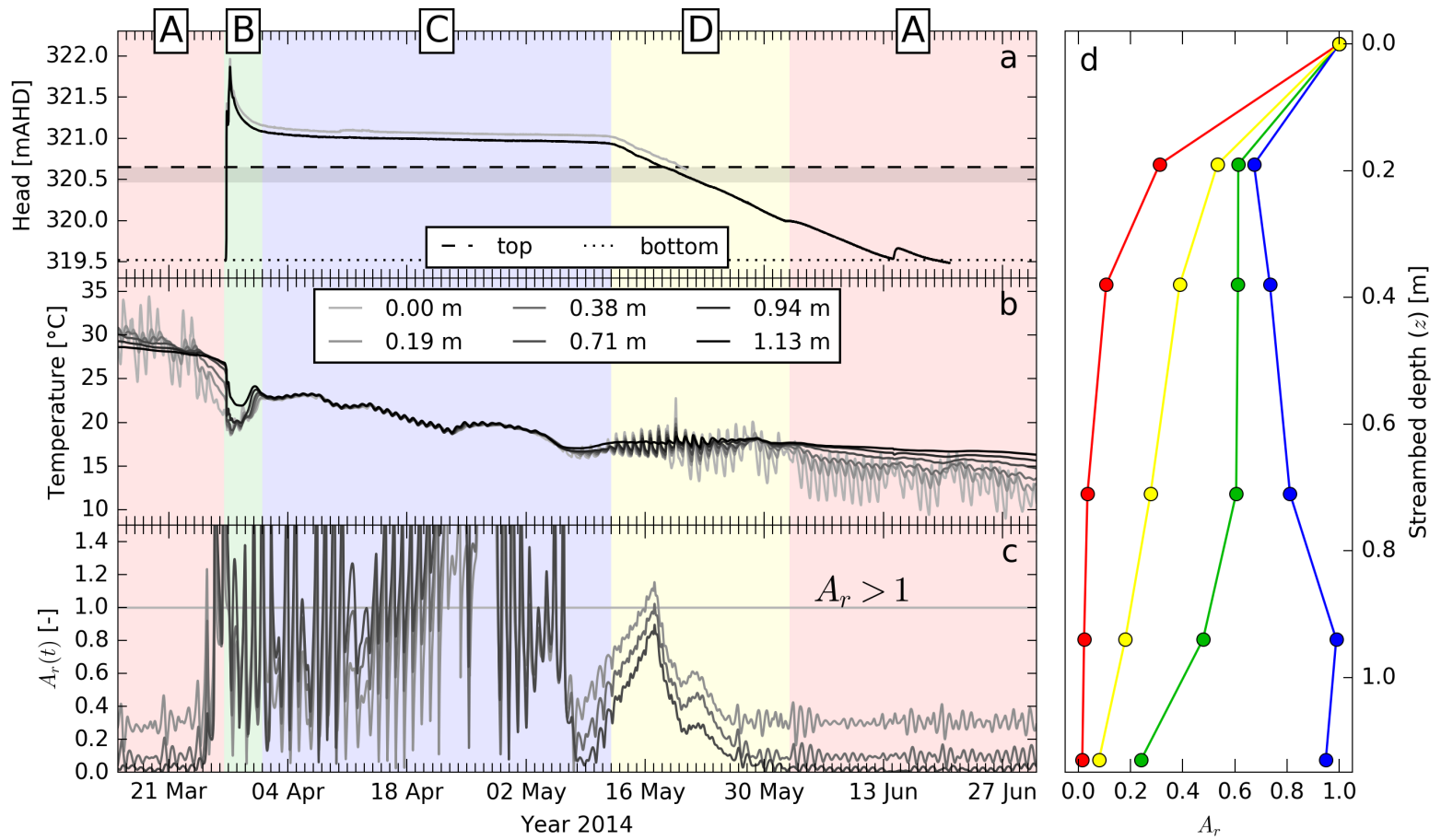

Figure 8: Streambed array T9 : a) Hydraulic head at the top and bottom of the array. The grey band indicates the depth interval in which temperature data is interpreted in Figure 7. b) Multi-level temperature records. b) Multi-level temperature records. c) Amplitude ratio time series $A_{r}(t)$ of the diel temperature component for 3 depths (same legend as panel b). d) Depth profiles of diel temperature amplitude ratios averaged over the time period corresponding to the colour coded flow regimes $A$-D labelled at the top of panel (a) and which are sketched in Figure 10

water saturation beneath the channel. Upon arrival of the water in the dry channel, the temperature rapidly changes over depth with an associated increase in the diel temperature amplitude (Figures $8 \mathrm{~b}$ and $9 \mathrm{~b}$ ). This reflects the highly transient infiltration of water which carries a contrasting temperature downwards [24]. Further, this marks a period of highly transient infiltration [29, 66] in particular for locations that show ephemeral behaviour (T4-T1 in Figure 7). The streambed saturation may be significantly delayed compared to the arrival of surface water (T11 in Figure 7). 

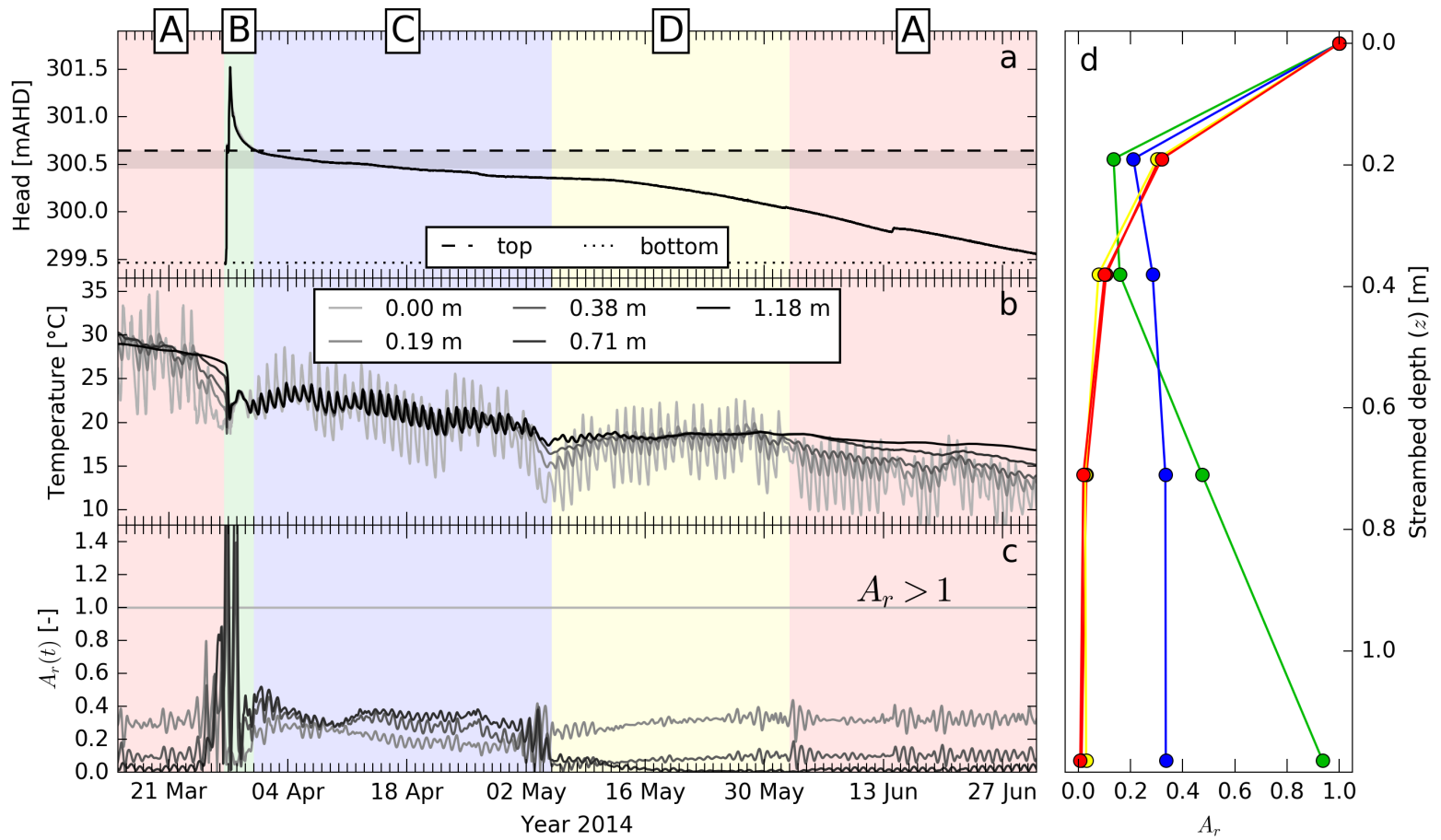

FiguRE 9: Streambed array T7 : a) Hydraulic head at the top and bottom of the array. The grey band indicates the depth interval in which temperature data is interpreted in Figure 7. b) Multi-level temperature records. c) Amplitude ratio time series $A_{r}(t)$ of the diel temperature component for 3 depths (same legend as panel b). d) Depth profiles of diel temperature amplitude ratios averaged over the time period corresponding to the colour coded flow regimes $A-D$ labelled at the top of panel (a) and which are sketched in Figure 10

[C] Pool-riffle sequence (blue) : This regime is characterised by water flow through pool-riffle sequences including varying proportions of both subsurface (hyporheic) and surface flow that is predominantly horizontal. It only occurs if the infiltrated water is not redistributed fast enough so that the groundwater table rises above the streambed surface thereby intersecting the channel topography. The duration of this regime varies depending on the lateral aquifer response time (ART), the rate at which the subsurface water mound redistributes [7]. Consequently, this regime is much shorter or may never be reached in locations that have a low ART. Further, the timing of the transition to the next flow 


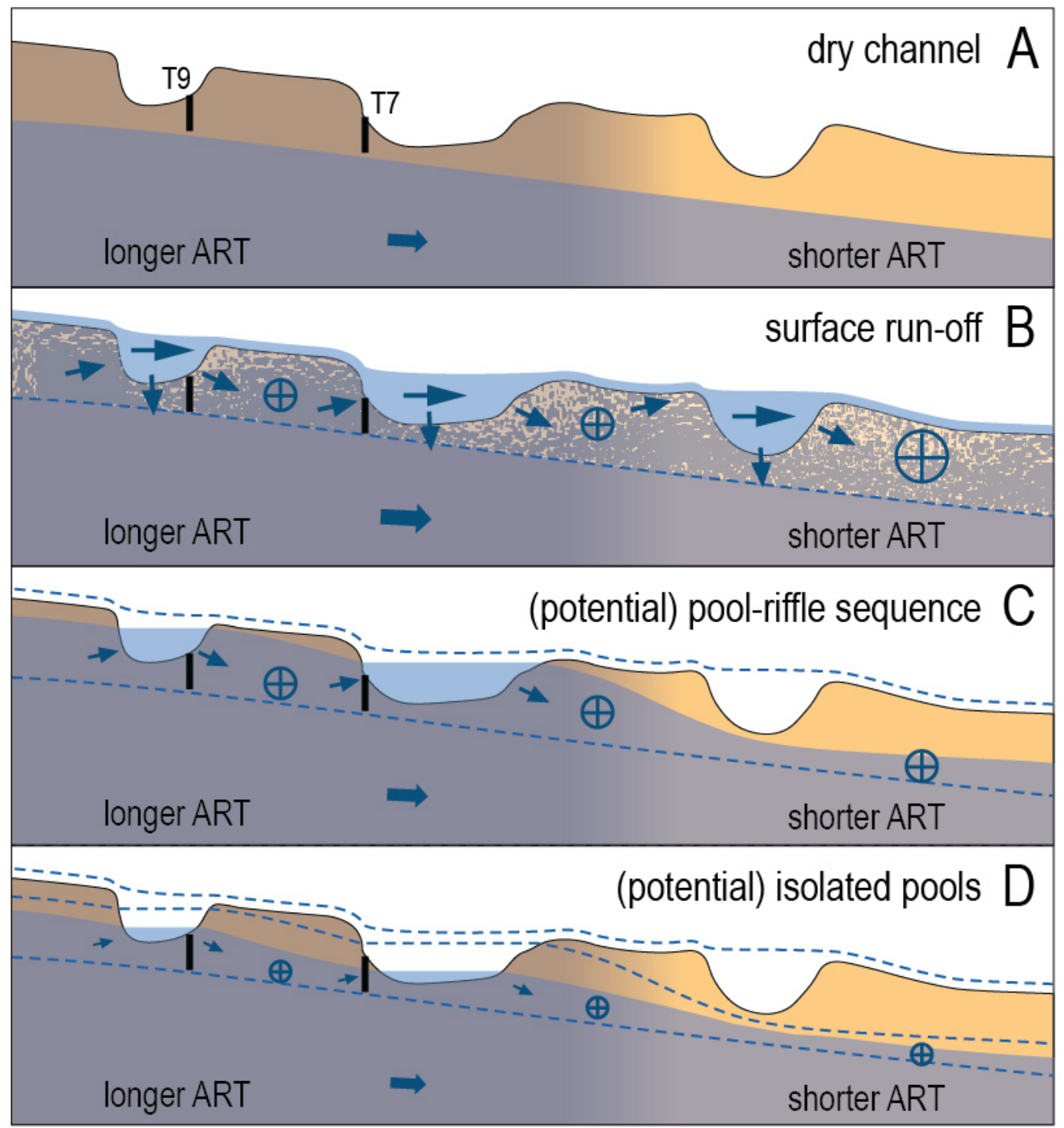

Figure 10: Conceptual model of the different hydrological regimes that occur during transitory surface water-groundwater interactions in ephemeral or intermittent streams. Note that while the regions of longer and shorter aquifer response time (ART, a measure for the redistribution rate of infiltrated water [7]) greatly simplify realistic conditions, it is reflective of our field conditions and provides a range of conditions which may be relevant to other studies. A variable ART also explains the potential occurrence of regime $\mathrm{C}$ and D. Note further that streambed arrays T9 and T7 are located to qualitatively reflect the measured water levels and thermal signatures (Figures 8 and 9). The hydrological and thermal conditions of this sequence is detailed in the discussion. 
regime depends on the local streambed morphology and is therefore somewhat ambiguous. The shallow subsurface temperatures during this regime are similar to those observed in perennial systems dominated by hyporheic exchange [67, 68].

During this flow regime, the locations show differing behaviour : T9 features an $A_{r}$-depth profile that is significantly different from dry conditions and indicates a downward flow component (Figure 8). In contrast, the shallower part of T7 indicates an upward flow component whereas the deeper part shows increasingly downward flow (Figure 9p. The difference between $\mathrm{T} 9$ and $\mathrm{T} 7$ are indicative of their different locations within the pool-riffle sequence and in relative elevation of water table relative to the ground surface (Figure 10). T7 was located at the end of a gravel bar with up-welling hyporheic flow at the top of the array throughout the short duration of the surface run-off. T9 was located at the downstream end of a pool.

Note that the array locations relative to the pool-riffle system will change as the water level recedes, and also due to potential erosion during surface run-off. It is noteworthy that during this flow regime the diel amplitude propagates to the lowest sensor in the sediment and can cause an amplitude ratio that is larger than unity $\left(A_{r}>1\right)$ thus violating the conditions required to apply vertical analytical heat tracing. In the absence of a subsurface thermal source, $A_{r}>1$ is an indicator for hyporheic flow with a significant horizontal component [47, 69].

[D] Cessation of riffle flow and drying of the isolated pools and sediments (yellow) : A steady decrease in hydraulic head indicates that water is redistributing in the subsurface leaving the channel sediments to dry out. Similar to (C), this regime may be bypassed under certain conditions. The increase of the diel temperature amplitude, particularly at the lower sensors, is an indication of a significant downward water flux.

Our conceptual model is supported by the fact that surface flow exists at locations when surface water further upstream has disappeared (Figure 4). Consequently, water contained in the shallow alluvium must move downstream and sideways as the overall water table elevation slowly falls below the lowest elevations of the streambed surface. We further note that the existence of these regimes was verified by visual observations made during numerous field trips throughout the hydrological sequence. This is further verified by 
time lapse images captured using a camera mounted beside the stream near BH20/T9, as described in a previous study [7].

\section{Conclusions}

We have shown how amplitude ratios of the diel component in temperature time series measured at two vertical locations in shallow streambeds can be used to detect saturation conditions and to characterise transitory flow conditions. This is an advantage over head measurements due to the lower cost involved and ease of installation which allows the possibility of a wider spatial deployment of sensors. Amplitude ratios depend on the sediment thermal diffusivity, which is a function of the different thermal properties of air or water occupying the pore space. While the dry streambed thermal diffusivity can be determined from temperature records acquired during dry periods, the saturated thermal diffusivity is always higher depending on the sediment properties. The likely difference between dry and saturated amplitude ratios does not exceed $\sim 0.175$ as illustrated using a Monte-Carlo analysis with probable ranges in matrix thermal properties available in the literature.

A small range of amplitude ratios exists for which interpretation of the state of saturation is ambiguous, i.e. either variably saturated sediments or full saturation with upward flow. The range of ambiguity is determined by the difference between dry and saturated streambed thermal diffusivity, which depends both on porosity and matrix thermal properties. However, when interpreted in combination with pressure data, which is indicative of whether or not water is present above the point of measurement, this range can still be used to reveal streambed processes.

We have applied this new approach to multi-level temperature data from streambed arrays deployed along a $\sim 12 \mathrm{~km}$ channel section. Hydraulic heads were measured simultaneously by the arrays as well as at co-located shallow piezometers. The data demonstrate that intermittent surface water-groundwater interactions are highly variable in space and time. The interpreted temperature and pressure data enable categorization of these interactions into four generic hydrological regimes that can occur sequentially in time : (A) dry channel, (B) rapid surface run-off along the channel, (C) pool-riffle sequence with horizontal hyporheic flow, (D) isolated pools. The duration of each regime will depend on the channel morphology as well as the lateral aquifer response time (ART) which controls the rate of groundwater redistribution. Our results illustrate that sequence $\mathrm{C}$ and $\mathrm{D}$ may not be reached in the case 
that the infiltrated water is redistributed fast enough so that the groundwater level does not rise above the streambed surface for a significant duration.

Such analysis enables determination of the intricate dynamics inherent to the connectivity between intermittent surface flow and groundwater and is directly relevant to other semi-arid and arid regions of the world [1]. Understanding such hydrological behaviour is imperative to conjunctive resource management in water-limited environments [2]. Furthermore, thermal conditions in the shallow streambed influence water quality through hydrochemical and biological processing and determine the ecological habitat [70, 1]. Our approach to monitoring, understanding and interpreting thermal regimes in intermittent and ephemeral streams can, therefore, improve spatiotemporal understandings of hyporheic processes and associated water quality dynamics, groundwater recharge, and when and how dryland streams support riparian ecosystems.

\section{Acknowledgements}

We are grateful for technical and field support provided by Evan Jensen, Edwina Davison, Calvin Li and to landowners in Mauls Creek (Philip Laird, Alistair Todd, and Steve Bradshaw) for giving access to the field sites. The figures in this manuscript were made with the help of Matplotlib [71. The data used in this analysis was collected with equipment provided by the Australian Federal Government financed National Collaborative Research Infrastructure Scheme (NCRIS, data available at : http://groundwater.anu.edu.au/fieldsite/maules-creek). We would like to thank the Cotton Catchment Communities CRC for their financial support (Cotton CRC projects 2.02.03 and 2.02.21). The elevation data in Figure 2 is courtesy of Geoscience Australia http://www.ga.gov.au. MOC was supported by the European Community's Seventh Framework Program (FP7/2007-2013) under grant agreement 299091. GCR was supported by the National Centre for Groundwater Research and Training (NCGRT), an Australian Government initiative supported by the Australian Research Council $(A R C)$ and the National Water Commission $(N W C)$. LJSH was supported by the NSW State Government's Research Acceleration and Attraction Program (RAAP) in the year 2016. We further thank the Editor Paolo D'Odorico as well as the AE and 2 reviewers (all anonymous) for handling and suggesting improvements to this manuscript during peer-review. 


\section{References}

[1] T. Datry, K. Fritz, C. Leigh, Challenges, developments and perspectives in intermittent river ecology, Freshwater Biology (2016) 1171-1180.

[2] L. R. Levick, D. C. Goodrich, M. Hernandez, J. Fonseca, D. J. Semmens, J. Stromberg, M. Tluczek, R. a. Leidy, M. Scianni, P. D. Guertin, W. G. Kepner, The Ecological and Hydrological Significance of Ephemeral and Intermittent Streams in the Arid and Semi-arid American Southwest, Technical Report, US Environmental Protection Agency and USDA/ARS So, 2008.

[3] J. Constantz, C. L. Thomas, G. Zellweger, Influence of diurnal variations in stream temperature on streamflow loss and groundwater recharge, Water Resources Research 30 (1994) 3253-3264.

[4] J. Lange, Dynamics of transmission losses in a large arid stream channel, Journal of Hydrology 306 (2005) 112-126.

[5] B. R. Scanlon, K. E. Keese, A. L. Flint, L. E. Flint, C. B. Gaye, W. M. Edmunds, I. Simmers, Global synthesis of groundwater recharge in semiarid and arid regions, Hydrological Processes 20 (2006) 3335-3370.

[6] M. Shanafield, P. G. Cook, Transmission losses, infiltration and groundwater recharge through ephemeral and intermittent streambeds : A review of applied methods, Journal of Hydrology 511 (2014) 518-529.

[7] M. O. Cuthbert, R. I. Acworth, M. S. Andersen, J. R. Larsen, A. M. McCallum, G. C. Rau, J. H. Tellam, Understanding and quantifying focused, indirect groundwater recharge from ephemeral streams using water table fluctuations, Water Resources Research 52 (2016) 827-840.

[8] T. R. Labbe, K. D. Fausch, Dynamics of intermittent stream habitat regulate persistence of a threatened fish at multiple scales, Ecological Applications 10 (2000) 1774-1791.

[9] I. Simmers, Understanding Water in a Dry Environment - hydrological processes in arid and semi-arid zones, volume 23, Taylor \& Francis, 2003. 
[10] R. G. Taylor, M. C. Todd, L. Kongola, L. Maurice, E. Nahozya, H. Sanga, A. M. MacDonald, Evidence of the dependence of groundwater resources on extreme rainfall in East Africa, Nature Climate Change 3 (2012) 374-378.

[11] M. O. Cuthbert, G. M. Ashley, A Spring Forward for Hominin Evolution in East Africa, PLoS ONE 9 (2014) e107358.

[12] Y. Wada, L. P. H. Van Beek, C. M. Van Kempen, J. W. T. M. Reckman, S. Vasak, M. F. P. Bierkens, Global depletion of groundwater resources, Geophysical Research Letters 37 (2010) L20402.

[13] T. Gleeson, W. M. Alley, D. M. Allen, M. A. Sophocleous, Y. Zhou, M. Taniguchi, J. Vandersteen, Towards sustainable groundwater use : Setting long-term goals, backcasting, and managing adaptively, Ground Water 50 (2012) 19-26.

[14] Y. Wada, L. P. H. van Beek, N. Wanders, M. F. P. Bierkens, Human water consumption intensifies hydrological drought worldwide, Environmental Research Letters 8 (2013) 034036.

[15] J. Constantz, C. L. Thomas, The Use of Streambed Temperature Profiles to Estimate the Depth, Duration, and Rate of Percolation Beneath Arroyos, Water Resources Research 32 (1996) 3597-3602.

[16] J. Constantz, D. Stonestrom, A. E. Stewart, R. Niswonger, T. R. Smith, Analysis of streambed temperatures in ephemeral channels to determine streamflow frequency and duration, Water Resources Research 37 (2001) $317-328$.

[17] W. B. Bull, Discontinuous ephemeral streams, Geomorphology 19 (1997) $227-276$.

[18] O. Dahan, B. Tatarsky, Y. Enzel, C. Kulls, M. Seely, G. Benito, Dynamics of flood water infiltration and ground water recharge in hyperarid desert, Ground Water 46 (2008) 450-461.

[19] P. Brunner, C. T. Simmons, P. G. Cook, Spatial and temporal aspects of the transition from connection to disconnection between rivers, lakes and groundwater, Journal of Hydrology 376 (2009) 159-169. 
[20] D. J. Irvine, P. Brunner, H.-J. H. Franssen, C. T. Simmons, Heterogeneous or homogeneous? Implications of simplifying heterogeneous streambeds in models of losing streams, Journal of Hydrology 424-425 (2012) 16-23.

[21] J. Constantz, Interaction between stream temperature, streamflow, and groundwater exchanges in alpine streams, Water Resources Research 34 (1998) 1609-1615.

[22] J. Constantz, C. L. Thomas, Stream bed temperature profiles as indicators of percolation characteristics beneath arroyos in the Middle Rio Grande Basin, USA, Hydrological Processes 11 (1997) 1621-1634.

[23] K. W. Blasch, T. P. a. Ferré, J. P. Hoffmann, A Statistical Technique for Interpreting Streamflow Timing Using Streambed Sediment Thermographs, Vadose Zone Journal 3 (2004) 936.

[24] J. Constantz, A. Stewart, R. Niswonger, L. Sarma, Analysis of temperature profiles for investigating stream losses beneath ephemeral channels, Water Resources Research 38 (2002) 1-13.

[25] B. K. W. Blasch, J. Constantz, D. A. Stonestrom, Thermal Methods for Investigating Ground-water Recharge, Technical Report, 2007.

[26] M. P. Anderson, Heat as a Ground Water Tracer, Ground Water 43 (2005) 951-968.

[27] J. Constantz, Heat as a tracer to determine streambed water exchanges, Water Resources Research 44 (2008) n/a-n/a.

[28] G. C. Rau, M. S. Andersen, A. M. McCallum, H. Roshan, R. I. Acworth, Heat as a tracer to quantify water flow in near-surface sediments, EarthScience Reviews 129 (2014) 40-58.

[29] K. W. Blasch, T. P. A. Ferré, J. P. Hoffmann, J. B. Fleming, Relative contributions of transient and steady state infiltration during ephemeral streamflow, Water Resources Research 42 (2006) W08405.

[30] L. J. Halloran, H. Roshan, G. C. Rau, M. S. Andersen, Calculating water saturation from passive temperature measurements in near-surface sediments : Development of a semi-analytical model, Advances in Water Resources 89 (2016) 67-79. 
[31] L. J. S. Halloran, G. C. Rau, M. S. Andersen, Heat as a tracer to quantify processes and properties in the vadose zone : A review, Earth-Science Reviews 159 (2016) 358-373.

[32] H. S. Carslaw, J. C. Jaeger, Conduction of heat in solids, 1959.

[33] R. W. Stallman, Steady one-dimensional fluid flow in a semi-infinite porous medium with sinusoidal surface temperature, Journal of Geophysical Research 70 (1965) 2821.

[34] S. Goto, Thermal response of sediment with vertical fluid flow to periodic temperature variation at the surface, Journal of Geophysical Research 110 (2005) B01106.

[35] G. De Marsily, Quantitative hydrogeology; groundwater hydrology for engineers, Academic Press, New York, NY, USA, 1986.

[36] D. W. Waples, J. S. Waples, A Review and Evaluation of Specific Heat Capacities of Rocks, Minerals, and Subsurface Fluids. Part 1 : Minerals and Nonporous Rocks, Natural Resources Research 13 (2004) 97-122.

[37] G. C. Rau, M. S. Andersen, R. I. Acworth, Experimental investigation of the thermal dispersivity term and its significance in the heat transport equation for flow in sediments, Water Resources Research 48 (2012) $\mathrm{n} / \mathrm{a}-\mathrm{n} / \mathrm{a}$.

[38] C. E. Hatch, A. T. Fisher, J. S. Revenaugh, J. Constantz, C. Ruehl, Quantifying surface water-groundwater interactions using time series analysis of streambed thermal records : Method development, Water Resources Research 42 (2006) n/a-n/a.

[39] M. O. Cuthbert, R. MacKay, Impacts of nonuniform flow on estimates of vertical streambed flux, Water Resources Research 49 (2013) 19-28.

[40] M. O. Cuthbert, An improved time series approach for estimating groundwater recharge from groundwater level fluctuations, Water Resources Research 46 (2010) n/a-n/a.

[41] J. Côté, J.-M. Konrad, A generalized thermal conductivity model for soils and construction materials, Canadian Geotechnical Journal 42 (2005) 443-458. 
[42] Y. Dong, J. S. McCartney, N. Lu, Critical Review of Thermal Conductivity Models for Unsaturated Soils, Geotechnical and Geological Engineering 33 (2015) 207-221.

[43] O. Johansen, Thermal Conductivity of Soils, Ph.D. thesis, University of Trondheim, 1975.

[44] W. Woodside, J. H. Messmer, Thermal Conductivity of Porous Media. I. Unconsolidated Sands, Journal of Applied Physics 32 (1961) 1688.

[45] NIST, Chemistry WebBook, 2017.

[46] C. Clauser, Heat Transport Processes in the Earths Crust, Surveys in Geophysics 30 (2009) 163-191.

[47] G. C. Rau, M. S. Andersen, A. M. McCallum, R. I. Acworth, Analytical methods that use natural heat as a tracer to quantify surface watergroundwater exchange, evaluated using field temperature records, Hydrogeology Journal 18 (2010) 1093-1110.

[48] T. C. Winter, J. W. Harvey, O. L. Franke, W. M. Alley, Ground water and surface water : a single resource, Technical Report 1139, U.S. Geological Survey, 1998.

[49] G. C. Rau, M. O. Cuthbert, A. M. McCallum, L. J. S. Halloran, M. S. Andersen, Assessing the accuracy of 1-D analytical heat tracing for estimating near-surface sediment thermal diffusivity and water flux under transient conditions, Journal of Geophysical Research F : Earth Surface 120 (2015) 1551-1573.

[50] M. S. Andersen, R. I. Acworth, Stream-aquifer interactions in the Maules Creek catchment, Namoi Valley, New South Wales, Australia, Hydrogeology Journal 17 (2009) 2005-2021.

[51] B. M. S. Giambastiani, A. M. McCallum, M. S. Andersen, B. F. J. Kelly, R. I. Acworth, Understanding groundwater processes by representing aquifer heterogeneity in the Maules Creek catchment, Namoi Valley (New South Wales, Australia), Hydrogeology Journal 20 (2012) 1027-1044. 
[52] A. M. McCallum, M. S. Andersen, G. C. Rau, R. I. Acworth, A 1-D analytical method for estimating surface water-groundwater interactions and effective thermal diffusivity using temperature time series, Water Resources Research 48 (2012).

[53] B. F. J. Kelly, W. A. Timms, M. S. Andersen, A. M. McCallum, R. S. Blakers, R. Smith, G. C. Rau, A. Badenhop, K. Ludowici, R. I. Acworth, Aquifer heterogeneity and response time : the challenge for groundwater management, Crop and Pasture Science 64 (2013) 1141-1154.

[54] A. M. McCallum, M. S. Andersen, G. C. Rau, J. R. Larsen, R. I. Acworth, River-aquifer interactions in a semiarid environment investigated using point and reach measurements, Water Resources Research 50 (2014) 2815-2829.

[55] M. B. Cardenas, Thermal skin effect of pipes in streambeds and its implications on groundwater flux estimation using diurnal temperature signals, Water Resources Research 46 (2010).

[56] P. Brunner, P. G. Cook, C. T. Simmons, Disconnected surface water and groundwater : From theory to practice, Ground Water 49 (2011) 460-467.

[57] M. Shanafield, P. G. Cook, P. Brunner, J. Mccallum, C. T. Simmons, Aquifer response to surface water transience in disconnected streams, Water Resources Research 48 (2012) W11510.

[58] P. Brunner, P. G. Cook, C. T. Simmons, Hydrogeologic controls on disconnection between surface water and groundwater, Water Resources Research 45 (2009) W01422.

[59] J. Keery, A. Binley, N. Crook, J. W. Smith, Temporal and spatial variability of groundwatersurface water fluxes : Development and application of an analytical method using temperature time series, Journal of Hydrology 336 (2007) 1-16.

[60] C. H. Luce, D. Tonina, F. Gariglio, R. Applebee, Solutions for the diurnally forced advection-diffusion equation to estimate bulk fluid velocity and diffusivity in streambeds from temperature time series, Water Resources Research 49 (2013) 488-506. 
[61] J. H. Fleckenstein, R. G. Niswonger, G. E. Fogg, River-Aquifer Interactions, Geologic Heterogeneity, and Low-Flow Management, Ground Water 44 (2006) 837-852.

[62] D. J. Irvine, R. H. Cranswick, C. T. Simmons, M. A. Shanafield, L. K. Lautz, The effect of streambed heterogeneity on groundwater-surface water exchange fluxes inferred from temperature time series, Water Resources Research 51 (2015) 198-212.

[63] U. Schwartz, Factors affecting channel infiltration of floodwaters in Nahal Zin basin, Negev desert, Israel, Hydrological Processes 30 (2016) 3704-3716.

[64] Y. Xie, P. G. Cook, P. Brunner, D. J. Irvine, C. T. Simmons, When Can Inverted Water Tables Occur Beneath Streams?, Groundwater 52 (2014) 769-774.

[65] G. Gianni, J. Richon, P. Perrochet, A. Vogel, P. Brunner, Rapid identification of transience in streambed conductance by inversion of floodwave responses, Water Resources Research 52 (2016) 2647-2658.

[66] J. Batlle-Aguilar, P. G. Cook, Transient infiltration from ephemeral streams : A field experiment at the reach scale, Water Resources Research 48 (2012) W11518.

[67] A. S. Arrigoni, G. C. Poole, L. A. K. Mertes, S. J. O’Daniel, W. W. Woessner, S. A. Thomas, Buffered, lagged, or cooled? Disentangling hyporheic influences on temperature cycles in stream channels, Water Resources Research 44 (2008).

[68] F. P. Gariglio, D. Tonina, C. H. Luce, Spatiotemporal variability of hyporheic exchange through a pool-riffle-pool sequence, Water Resources Research 49 (2013) 7185-7204.

[69] H. Roshan, G. C. Rau, M. S. Andersen, I. R. Acworth, Use of heat as tracer to quantify vertical streambed flow in a two-dimensional flow field, Water Resources Research 48 (2012).

[70] F. Gallart, N. Prat, E. M. Garca-Roger, J. Latron, M. Rieradevall, P. Llorens, G. G. Barbera, D. Brito, A. M. De Girolamo, A. Lo Porto, A. Buffagni, S. Erba, R. Neves, N. P. Nikolaidis, J. L. Perrin, E. P. 
${ }_{892}$ Querner, J. M. Quinonero, M. G. Tournoud, O. Tzoraki, N. Skoulikidis, R. Gamez, R. Gomez, J. Froebrich, A novel approach to analysing the regimes of temporary streams in relation to their controls on the composition and structure of aquatic biota, Hydrology and Earth System Sciences 16 (2012) 3165-3182.

[71] J. D. Hunter, Matplotlib : A 2D Graphics Environment, Computing in Science \& Engineering 9 (2007) 90-95. 